\title{
Degradation of Spacesuit Fabrics in Low Earth Orbit
}

James R. Gaier, Sammantha M. Baldwin, Angela D. Folz, Deborah L. Waters,

Terry R. McCue, and Donald A. Jaworske

Glenn Research Center, Cleveland, Ohio

Gregory W. Clark, Kerry J. Rogers, Brittany Batman, John Bruce, and Tsega Mengesu

Manchester College, North Manchester, Indiana 


\section{NASA STI Program . . . in Profile}

Since its founding, NASA has been dedicated to the advancement of aeronautics and space science. The NASA Scientific and Technical Information (STI) program plays a key part in helping NASA maintain this important role.

The NASA STI Program operates under the auspices of the Agency Chief Information Officer. It collects, organizes, provides for archiving, and disseminates NASA's STI. The NASA STI program provides access to the NASA Aeronautics and Space Database and its public interface, the NASA Technical Reports Server, thus providing one of the largest collections of aeronautical and space science STI in the world. Results are published in both non-NASA channels and by NASA in the NASA STI Report Series, which includes the following report types:

- TECHNICAL PUBLICATION. Reports of completed research or a major significant phase of research that present the results of NASA programs and include extensive data or theoretical analysis. Includes compilations of significant scientific and technical data and information deemed to be of continuing reference value. NASA counterpart of peer-reviewed formal professional papers but has less stringent limitations on manuscript length and extent of graphic presentations.

- TECHNICAL MEMORANDUM. Scientific and technical findings that are preliminary or of specialized interest, e.g., quick release reports, working papers, and bibliographies that contain minimal annotation. Does not contain extensive analysis.

- CONTRACTOR REPORT. Scientific and technical findings by NASA-sponsored contractors and grantees.
- CONFERENCE PUBLICATION. Collected papers from scientific and technical conferences, symposia, seminars, or other meetings sponsored or cosponsored by NASA.

- SPECIAL PUBLICATION. Scientific, technical, or historical information from NASA programs, projects, and missions, often concerned with subjects having substantial public interest.

- TECHNICAL TRANSLATION. Englishlanguage translations of foreign scientific and technical material pertinent to NASA's mission.

Specialized services also include creating custom thesauri, building customized databases, organizing and publishing research results.

For more information about the NASA STI program, see the following:

- Access the NASA STI program home page at http://www.sti.nasa.gov

- E-mail your question to help@sti.nasa.gov

- Fax your question to the NASA STI Information Desk at 443-757-5803

- Phone the NASA STI Information Desk at 443-757-5802

- Write to: STI Information Desk NASA Center for AeroSpace Information 7115 Standard Drive Hanover, MD 21076-1320 
NASA/TM-2012-217682

AIAA-2012-3573

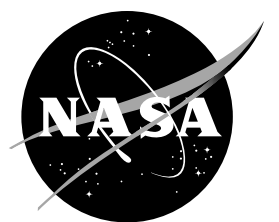

\section{Degradation of Spacesuit Fabrics in Low Earth Orbit}

James R. Gaier, Sammantha M. Baldwin, Angela D. Folz, Deborah L. Waters,

Terry R. McCue, and Donald A. Jaworske

Glenn Research Center, Cleveland, Ohio

Gregory W. Clark, Kerry J. Rogers, Brittany Batman, John Bruce, and Tsega Mengesu Manchester College, North Manchester, Indiana

Prepared for the

42nd International Conference on Environmental Systems

sponsored by the American Institute of Aeronautics and Astronautics

San Diego, California, July 15-19, 2012

National Aeronautics and

Space Administration

Glenn Research Center

Cleveland, Ohio 44135 


\section{Acknowledgments}

This work is the result of a great deal of effort by a sizable team of dedicated professionals from many organizations, all of whom the author would like to thank. Samples were provided by M.A.B. Meador of the NASA Glenn Research Center (GRC), J.J. Kosmo of the NASA Johnson Space Center, and J. Ware of ILC Dover. E.A. Sechkar (Arctic Slope Regional Corporation) and F.P. Lam (Jacobs Sverdrup) provided engineering and fabrication for the flight and analysis hardware. Financial support was provided by the Exploration Technology Development Program’s Dust Mitigation Project (M.J. Hyatt, GRC).

Trade names and trademarks are used in this report for identification only. Their usage does not constitute an official endorsement, either expressed or implied, by the National Aeronautics and Space Administration.

Level of Review: This material has been technically reviewed by technical management.

Available from

NASA Center for Aerospace Information 7115 Standard Drive

Hanover, MD 21076-1320
National Technical Information Service 5301 Shawnee Road Alexandria, VA 22312

Available electronically at http://www.sti.nasa.gov 


\title{
Degradation of Spacesuit Fabrics in Low Earth Orbit
}

\author{
James R. Gaier, Sammantha M. Baldwin, ${ }^{*}$ Angela D. Folz, \\ Deborah L. Waters, Terry R. McCue, and Donald A. Jaworske \\ National Aeronautics and Space Administration \\ Glenn Research Center \\ Cleveland, Ohio 44135 \\ Gregory W. Clark, Kerry J. Rogers, Brittany Batman, John Bruce, and Tsega Mengesu \\ Manchester College \\ North Manchester, Indiana 46962
}

\begin{abstract}
Six samples of pristine and dust-abraded outer layer spacesuit fabrics were included in the Materials International Space Station Experiment-7, in which they were exposed to the wake-side low Earth orbit environment on the International Space Station (ISS) for 18 months in order to determine whether abrasion by lunar dust increases radiation degradation. The fabric samples were characterized using optical microscopy, optical spectroscopy, field emission scanning electron microscopy, atomic force microscopy, and tensile testing before and after exposure on the ISS. Comparison of pre- and post-flight characterizations showed that the environment darkened and reddened all six fabrics, increasing their integrated solar absorptance by 7 to 38 percent. There was a decrease in the ultimate tensile strength and elongation to failure of lunar dust abraded Apollo spacesuit fibers by a factor of four and an increase in the elastic modulus by a factor of two.
\end{abstract}

\section{Nomenclature}

\begin{tabular}{|c|c|}
\hline AFM & atomic force microscope \\
\hline $\mathrm{AO}$ & atomic oxygen \\
\hline AlFEP & vapor-deposited aluminum backed FEP film \\
\hline ASTM & American Society for Testing and Materials \\
\hline EDS & Energy-Dispersive X-ray Spectroscopy \\
\hline EM & electromagnetic \\
\hline FEP & fluorinated ethylene propylene \\
\hline FESEM & Field Emission Scanning Electron Microscopy \\
\hline HST & Hubble Space Telescope \\
\hline ISS & International Space Station \\
\hline JSC-1A & lunar simulant \\
\hline LEO & low Earth orbit \\
\hline MISSE & Materials International Space Station Experiment \\
\hline PEC & passive Experiment Container \\
\hline PGA & pressure garment assembly \\
\hline PTFE & polytetrafluoroethylene \\
\hline UV & ultraviolet \\
\hline$\alpha$ & integrated solar absorptance \\
\hline$\lambda$ & wavelength \\
\hline$\rho(\lambda)$ & wavelength-dependent total reflectivity \\
\hline
\end{tabular}

* Undergraduate Student Research Program (USRP) Intern 


\subsection{Introduction}

During the Apollo missions, lunar dust was more problematic than anticipated. Post-mission documents reveal that there were difficulties with contaminated surfaces, clogged mechanisms, compromised seals, confusion of navigation equipment, degrading of radiators, irritation of eyes and lungs, and the abrasion of surfaces, including the spacesuits (Ref. 1). The Apollo spacesuits were exposed to the lunar surface environment for less than $24 \mathrm{hr}$, but even in this short period of time the suits showed appreciable wear. Apollo 12 astronaut Pete Conrad remarked, "We must have had more than a hundred hours suited work with the same equipment, and the wear was not as bad on the training suits as it is on these flight suits in just the eight hours we were out." (Ref. 2). For example, Figure 1 shows a hole abraded through the outer layer of Harrison Schmitt's Apollo 17 suit above the boot. If long term missions to the Moon or other extraterrestrial surfaces are going to be undertaken, the mechanisms of this degradation must be understood and mitigated.

The outer layer of the Apollo-era pressure garment assembly (PGA) is made from fluorinated ethylene propylene (FEP) and modern space suit PGAs from the closely related polytetrafluoroethylene (PTFE). FEP was also used as a thermal control material on the Hubble Space Telescope (HST). This was found to degrade with severe cracking after 6.8 yr exposure to the space environment (Ref. 3). The primary cause of the degradation is thought to have been polymer chain scission by particle and electromagnetic (EM) radiation combined with thermal cycling. Heating the shorter polymer chains facilitated crystallization, resulting in a far more brittle material (Refs. 3 and 4). Because the extinction coefficient for high energy UV radiation is so large, it is absorbed primarily the surface of a material. Since dust abrasion increases the surface area of a material, there is concern that abrasion may increase radiation degradation.

The International Space Station (ISS) is a laboratory orbiting about $350 \mathrm{~km}(280$ to $460 \mathrm{~km})$ above the surface of the Earth, traveling at a speed of about $28,000 \mathrm{~km} / \mathrm{hr}$. It is a joint project among the space agencies of the United States (NASA), Russia (RKA), Japan (JAXA), Canada (CSA) and 11 European countries (ESA). The ISS has been continuously staffed since November 2, 2000. Astronauts and cosmonauts from 16 countries have worked on it, and it has been visited by five space tourists.

Although most of the experimentation that has been conducted aboard the ISS has occurred inside the pressurized compartments, some researchers have taken advantage of its unique position to study the space environment from outside. The Materials International Space Station Experiment (MISSE) is a series of experiments mounted externally on the ISS that investigate the effects of long-term exposure of

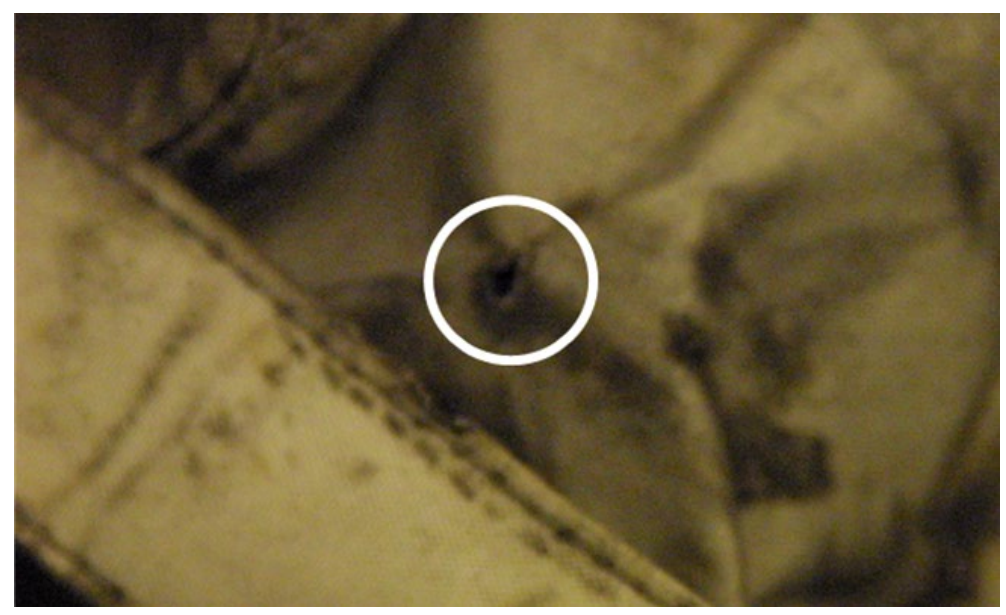

Figure 1.-Hole worn through the outer layer of Harrison Schmitt's Apollo 17 space suit above the boot. 
materials to the low Earth orbital (LEO) environment. The materials are mounted in suitcase-sized experiment packages called Passive Experiment Containers (PECs) that are mounted with half of the exposure surface facing the direction of motion of ISS through the exosphere (ram direction) and half the other side (wake direction), or alternately with one surface facing away from the Earth (zenith) and the opposite facing towards the Earth (nadir).

The concern about the synergistic effects of abrasion and radiation damage prompted the inclusion of the Spacesuit Fabrics Exposure Experiment on the Materials International Space Station Experiment-7 (MISSE-7). In this experiment, pristine and dust-abraded samples of outer layer spacesuit fabrics were flown on the wake side PEC for approximately 18 months, from November 2009 to May 2011. They were exposed to the space radiation environment of LEO, which is similar to that of the Moon, though reduced in particle radiation because many of the solar wind ions are captured by the van Allen radiation belts, well above ISS orbit. The long-term exposure in LEO shed light on the extent to which spacesuit fabrics degraded in long-term exposure on the Moon, and how dust abrasion affects it. Unintended exposure to atomic oxygen (AO) during the reorientation of the ISS introduced an additional degradation mechanism.

The Spacesuit Fabric Exposure Experiment was assembled at the NASA Glenn Research Center and integrated into the wake side of PEC-7B at the NASA Langley Research Center. It was launched from the NASA Kennedy Space Center aboard the Space Shuttle Atlantis (STS-129) on November 16, 2009. On November 23, astronaut Randolph Bresnik removed MISSE-7 from the cargo bay and installed it on ELC-2, located on the S3 Truss segment. Figure 2 shows MISSE-7 as mounted on the ISS.

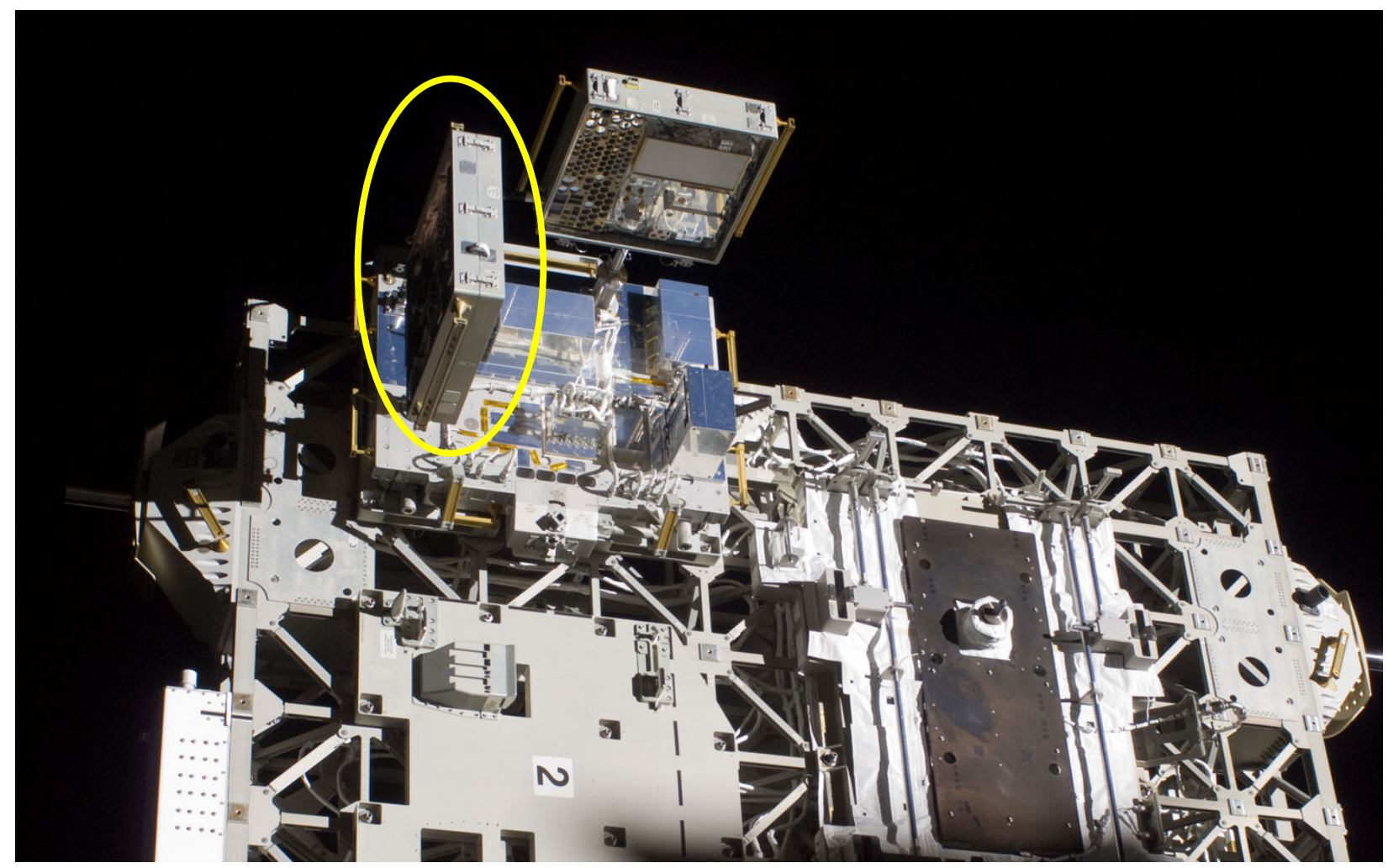

Figure 2.-MISSE-7 as mounted to ELC-2 on the ISS, with the PEC 7-B circled. The direction of motion in orbit is right to left, and the Spacesuit Fabric Exposure Experiment was mounted on the right side as viewed in this photograph. 


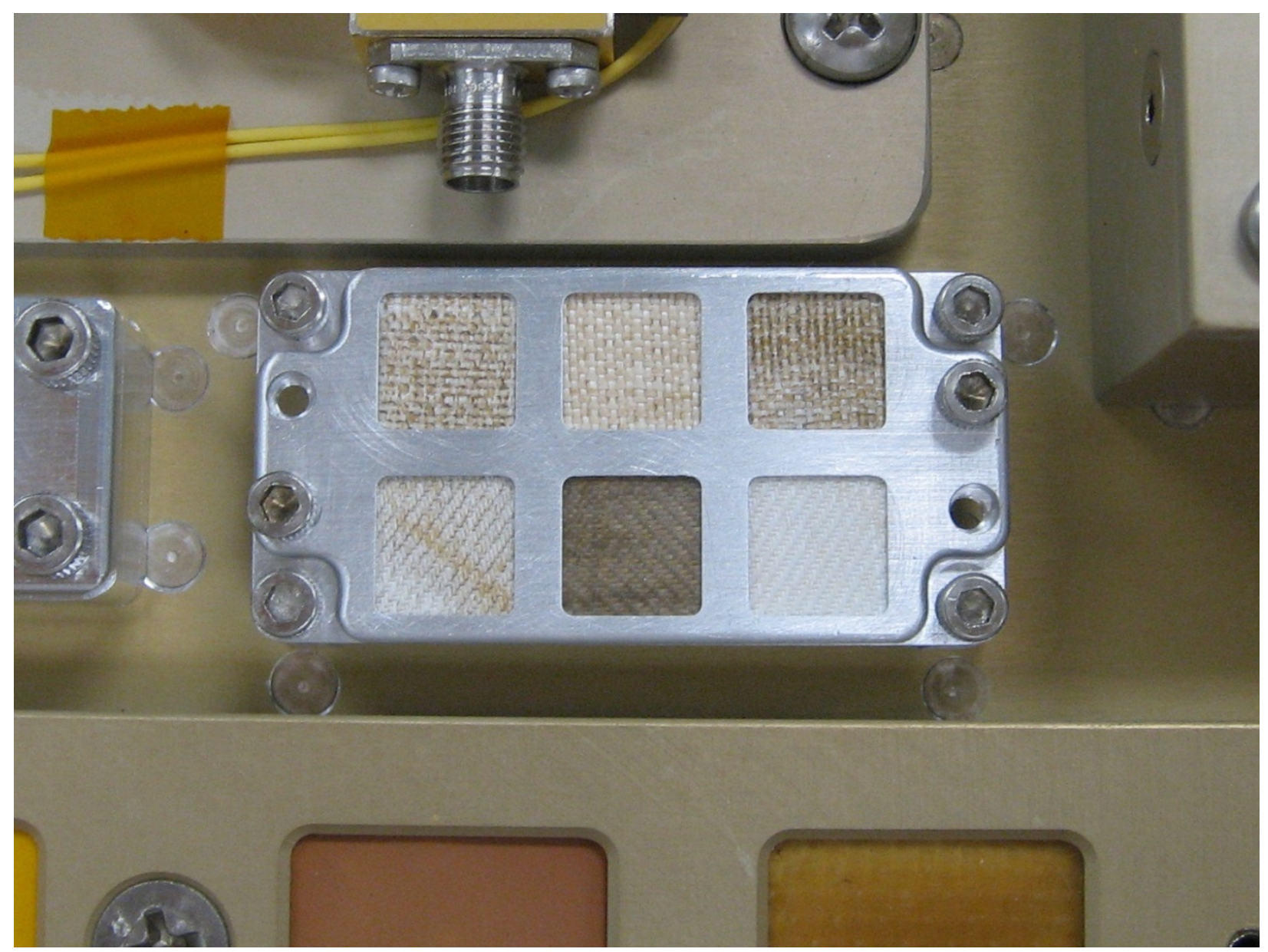

Figure 3.-The Spacesuit Fabric Exposure Experiment after recovery in the lab, before being removed from MISSE-7, showing in its local flight environment.

After 554 days in orbit, on May 20, 2011, astronauts Drew Feustel and Greg Chamitoff retrieved MISSE-7 and mounted it into the payload bay of Space Shuttle Endeavor. This was STS-134, the $25^{\text {th }}$ and final flight of Endeavor, which returned MISSE-7 to Earth on June 1. MISSE-7 was transferred to the NASA Langley Research Center, and on July 12 the experiment was first recovered and photographed (Figure 3). De-integration occurred on July 21 and the experiment was returned to the NASA Glenn Research Center on July 26. Analysis was started almost immediately, in case reactions with air or laboratory humidity would induce further changes. No visual evidence of any such changes was observed. All analyses were completed by mid-December 2011.

The preparation and pre-flight characterization of the fabric samples have been described previously (Ref. 5), as has the post-flight characterization (Ref. 6). A summary of the changes in the fabrics after 18 months of space exposure is the focus of this study.

\subsection{Methods and Materials}

\subsection{Materials}

The MISSE-7 Spacesuit Fabrics Exposure Experiment consists of six samples of spacesuit fabric. During the Apollo program, the outer surface of the PGA was made of woven FEP fabric. Although most of the PGAs were made with a plain-weave FEP, in some cases a twill-weave FEP was used. Three of the samples were of twill weave FEP. One was mounted as received (pristine), and a second was abraded 
with JSC-1A lunar simulant, as described below. A small piece from the left knee region of the PGA worn on the lunar surface for $7.8 \mathrm{hr}$ by Alan Bean during Apollo 12, which was a twill weave, was obtained and included in this experiment as well. This was one of the most heavily soiled portions of the Bean PGA. The samples were about $1 \mathrm{~cm}$ square, which was not small compared to the measurement area for photography, microscopic imaging, energy dispersive x-ray spectroscopy, or total reflectance spectroscopy. While the gauge length was smaller than typical for tensile testing, the aspect ratio of the filaments was sufficiently high, and the standard deviation was not atypical for these sorts of tests.

PGA design has progressed since the Apollo era, and the suits worn by astronauts in their return to the Moon will probably not have an outer layer of woven FEP. The current PGAs used in Space Shuttle and International Space Station EVAs use Ortho-fabric (Fabric Development) as the outermost layer. Orthofabric is a two layer plain weave face tied to back of 400 denier Gortex (W.L. Gore \& Associates), 200 denier Nomex (DuPont) and 400 denier Kevlar (DuPont). The yarn count is $51 \times 41$ on the face, and $39 \times 33$ on the back. The fabric weight is $15.0 \mathrm{oz} / \mathrm{yd}^{2}\left(0.355 \mathrm{~kg} / \mathrm{m}^{2}\right)$, with a thickness of 0.027 in $(0.69 \mathrm{~mm})$ (Ref. 7). The outer Gortex layer of is made from expanded PTFE, so although the two fabric types are very different, they both have fluorinated hydrocarbons as the outermost material. Three samples of Ortho-fabric were flown as part of the MISSE-7 Spacesuit Fabrics Exposure Experiment as well, with one being pristine, a second abraded with JSC-1A to the same level as the FEP, and the third being abraded with JSC-1A for twice as long.

\subsection{Dust Abrasion}

A Dust Abrasion of EVA Fabric Protocol was developed as a standardized set of procedures by which to abrade PGA fabrics for the MISSE-7 experiment (Ref. 8). The goal was to reproduce damage seen on Alan Bean's Apollo 12 suit. An ASTM standard test (Ref. 9) was modified so that damage was inflicted on small patches of fabric using loose lunar dust simulant, rather than an abrasion wheel. A photograph of the abrasion apparatus in shown in Figure 4. The fabric was mounted on the horizontal wheel and covered with a thin layer of JSC-1A lunar simulant which was plasma activated in the Lunar Dust Adhesion Bell Jar at the NASA Glenn Research Center, a high fidelity lunar environment simulation chamber. Without breaking vacuum, the wheel was rotated at $70 \mathrm{rpm}$. As it spins, it also spins the two vertically mounted abrasion wheels. These are slightly offset from the horizontal rotation axis so that one scuffs in and the other scuffs out. One sample of FEP fabric and one sample of Ortho-fabric were thus abraded for 8000 cycles. A second Ortho-fabric sample was abraded for 16,000 cycles, and will be referred to as the $2 \times$ abraded sample. The protocol is detailed in the pre-flight report (Ref. 5).

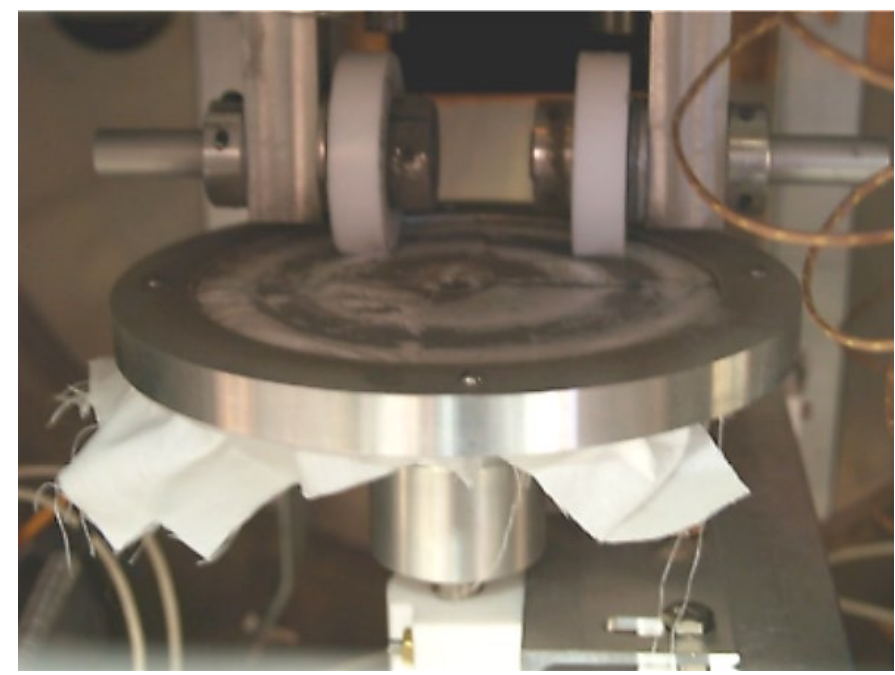

Figure 4.-Apparatus used to abrade selected PGA fabric samples with JSC-1A lunar simulant. 


\subsection{Photography and Microscopy}

To the extent possible, pre-flight and post-flight analyses were done using the same protocols, and these are also detailed in the pre-flight report (Ref. 5). Survey photos, such as that shown in Figure 3, were taken of the samples in the sample holder to record the orientation and local environment of each sample in the flight configuration. Imaging included optical microscopy at magnifications of $7.1 \times, 10 \times$, 25×, 50×, and 100×; Field Emission Scanning Electron Microscopy (FESEM) at 50×, 100×, 250×, 1000×, and $4000 \times$ and Atomic Force Microscopy (AFM) with scanning fields of $60 \mu \mathrm{m}, 10 \mu \mathrm{m}, 1 \mu \mathrm{m}$, and 100 $\mathrm{nm}$. The one aspect that was different between the pre-flight and post-flight analyses was the sampling areas. Whereas one of the goals of the pre-flight characterization was to establish the baseline structure, in the post-flight analysis changes and anomalies were the target. For example, in the FESEM five regions were surveyed pre-flight, but only two major regions of the post-flight, one that was exposed and one that was shielded by the sample holder. Within those regions images were taken that were representative of the whole, and of areas of anomalous wear.

In addition to survey photos taken of the entire sample holder, post-flight photographs were taken with the samples illuminated by a UV lamp. Fluorescence under UV illumination can indicate the presence of contamination or sample degradation. Energy dispersive x-ray spectroscopy (EDS) was also used post-flight to examine the samples for contamination. This was done in conjunction with the FESEM such that the elemental composition of specific microscopic areas of the samples could be determined.

\subsection{Total Reflectance Spectroscopy}

Optical spectroscopy was performed on the fabrics to look for signs of degradation. Of particular concern was whether the thermal properties, primarily the integrated solar absorptance, $\alpha$, would increase as this would impose an additional heat load on the suit. Total reflectivity $(\rho(\lambda))$, was measured with a Cary 5000 (Varian) spectrophotometer equipped with an integrating sphere over wavelengths $(\lambda)$ from 250 to $2500 \mathrm{~nm}$ in increments of $1 \mathrm{~nm}$, at a scan rate of $600 \mathrm{~nm} / \mathrm{min}$. A deuterium lamp was used to illuminate the samples to measure the 250 to $350 \mathrm{~nm}$ data, and a halogen lamp to illuminate the samples to measure the 350 to $2500 \mathrm{~nm}$ data. Immediately prior to measuring each sample, a spectrum of the Spectralon was collected as a sample, to determine whether the baseline was still valid. In all instances the deviations in the baseline were less than 1 percent. The integrated solar $\alpha$ of each sample was determined from the convolution of the scaled $\rho(\lambda)$ with the ASTM air mass zero solar spectral irradiance table E-490-00 and expressed as a fraction of the solar spectrum.

\subsection{Mechanical Properties}

Individual filaments from the Alan Bean sample were tensile tested to measure the ultimate tensile strength, elongation, and Young's modulus of fibers. Pre- and post-flight values were compared to measure mechanical degradation. Only the Alan Bean fibers were tested because the FEP fabric used for the pristine and abraded FEP samples was constructed of thicker fibers (on the order of $300 \mu \mathrm{m}$ in diameter as opposed to an average $23 \mu \mathrm{m}$ for the Bean fibers) as was the Ortho-fabric outer layer PTFE fibers (on the order of $500 \mu \mathrm{m}$ in diameter). The protocol described below was not effective for these thicker fibers because they would slip out of the adhesive before breaking. Future testing should include developing a method to tensile test these thicker fibers.

The ASTM Standard Test Method for Tensile Strength and Young's Modulus of Fibers was used to develop the tensile test protocol (Ref. 10), each fiber was first mounted on a 53- by 15-mm tab cut from an index card using the Reltek Teflon Bonding Kit procedure (Reltek, LLC). A 1/8 in. (3.1 mm) diameter hole punch was used to punch three holes in the center of the tab, as shown in Figure 5. After the tab is mounted in the instrument, the index card was cut along the dotted line such that only the fiber connects the two ends of the tab. 

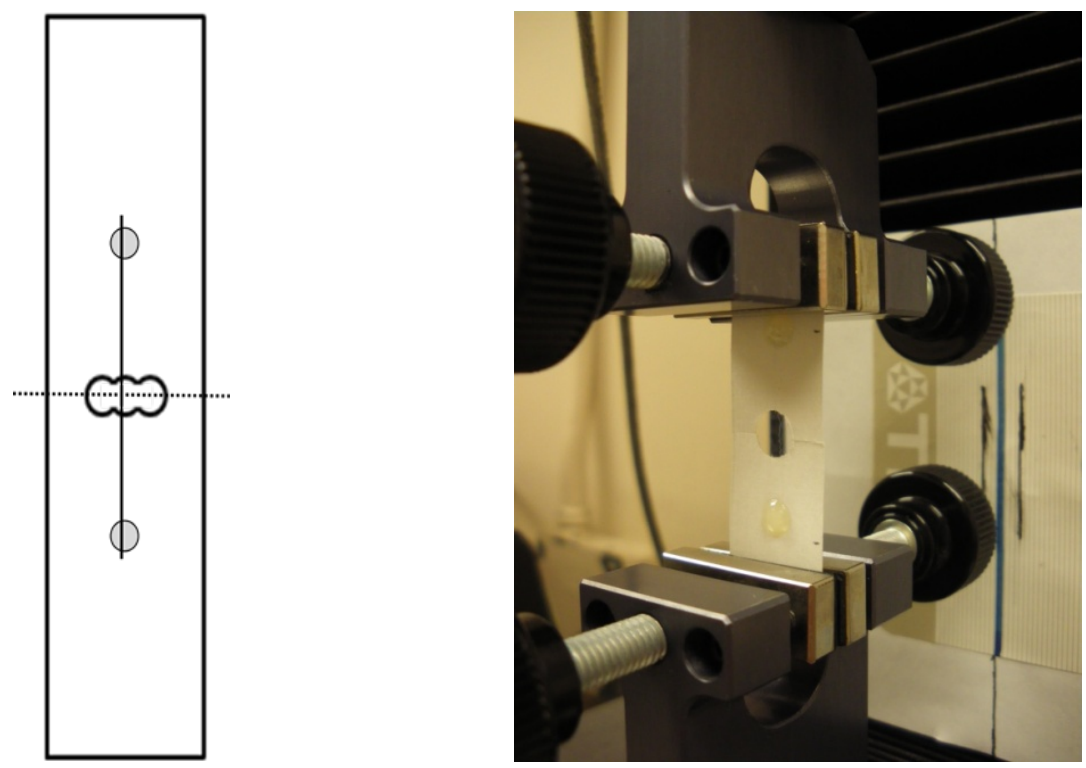

Figure 5.-Geometry of the tabs the fibers mounted with adhesive (shown as grey circles) for the tensile test. After mounting the tab in the tensile tester, the tab was cut along the dotted line so that the resulting halves were connected only by the fiber.

The tensile tester was set to a start threshold of $0.01 \mathrm{~N}$, end test of $266 \mathrm{~s}$, and $\log$ rate of $30.10 \mathrm{~Hz}$. The pre-flight Bean fibers were pulled at a test rate of $203.2 \mathrm{~mm} / \mathrm{min}$. The post-flight fibers were pulled at a test rate of $12.7 \mathrm{~mm} / \mathrm{min}$ because they were more brittle so at higher test rates they would break before the tensile tester could register any data. The tensile test data and the average pre-flight and post-flight fiber diameters (obtained from FESEM photomicrographs by averaging the diameter in 10 positions on four fibers in each category) were used to calculate the ultimate tensile strength, elongation at failure, and Young's modulus for each fiber. The mean and standard deviation of each value was calculated for preflight and post-flight fibers.

\subsection{Results and Discussion}

\subsection{Survey Photography}

Upon return of the flight samples to the NASA Glenn Research Center, they were removed from the Kapron they were bagged in and photographed. Figure 6 compares the flight samples (right) with control samples (left) that were treated identically, but not flown in space. It can be seen in the photograph that space exposure darkened the fabrics and gave them a somewhat reddish tint. This will be explored quantitatively in the spectroscopy section of the study. A dark streak was noted on the space-exposed sample (d) that stretches diagonally across the abraded FEP fabric. There was no evidence of this streak in the pre-flight photographs, and study of the flight environment around this sample did not yield a potential contamination source. No additional details were revealed when the samples were illuminated by UV light. More discussion of the streak appears in the sections on EDS and optical spectroscopy.

It was noted that the silver plated stainless steel hex nuts which were below the capscrews shown in Figure 6 turned black during the experiment. This was probably due to exposure to atomic oxygen (AO) in LEO during those periods when the ISS was reoriented such that the samples were exposed to the ram facing environment.

After the initial photography, the flight samples were removed from the sample holder. After removing the assembly screws, the sample holder was placed face down on a Kapron surface and the base plate was removed. When the aluminum shims were removed to reveal the back of the samples, no 


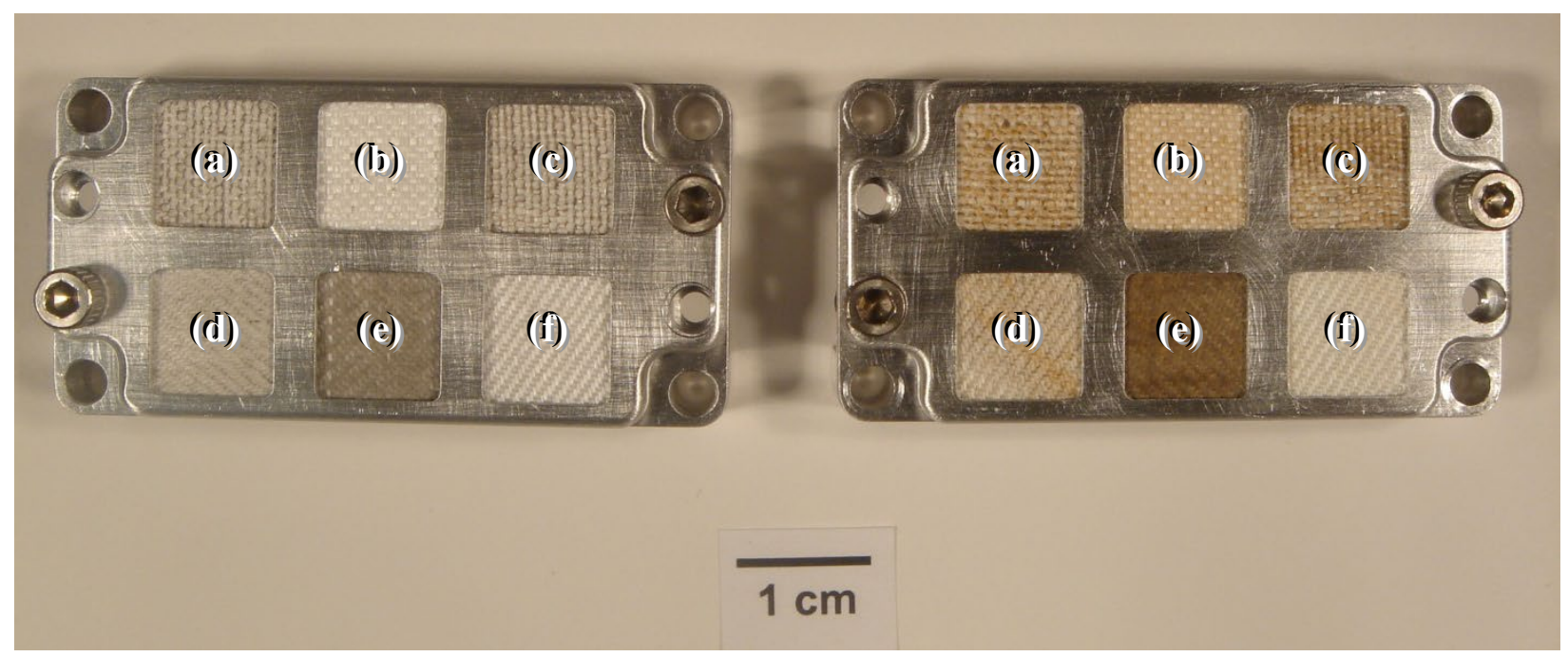

Figure 6.-Photograph of the control (left) and post-flight (right) MISSE-7 Spacesuit Fabric Exposure Experiment. Samples include abraded Ortho-fabric (a), pristine Ortho-fabric (b), double abraded Ortho-fabric (c), abraded Apollo era fabric (d), Alan Bean Apollo 12 fabric (e), and pristine Apollo era fabric (f).

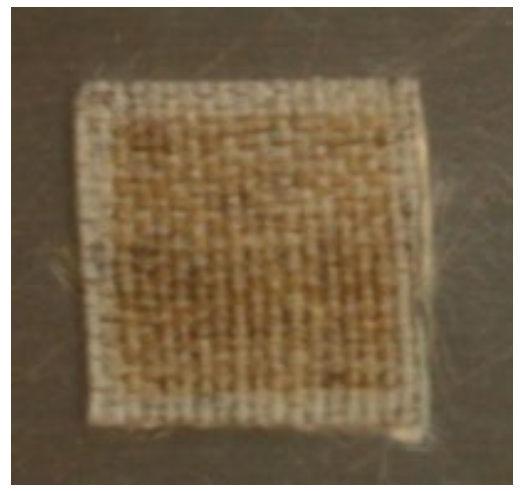

Figure 7.-Photograph of the $2 \times$ dust-abraded Ortho-fabric sample after removal from the samples holder. Note that the fabric was darkened except in those regions covered by the sample holder. The other five fabric samples showed the same discoloration pattern.

indications of contamination were evident. When the samples were removed from the flight holder, the perimeter area of the fabric that was shielded from the environment by being under the edge of the sample holder was readily visible in Figure 7. Space exposure similarly darkened all of the samples. Each sample was immediately transferred to its own sample handler (Ref. 5) so that they could be imaged in the optical microscope, the FESEM, and the AFM without needing to further handle the fabrics.

\subsection{Microscopic Imaging}

\subsubsection{Pristine FEP Fabric}

Images of all PGA fabric samples before and after space exposure taken with the light microscope, the FESEM, and the AFM are collected in appendices of the pre-flight and post-flight reports (Refs. 5 and 6). At low magnification, optical microscopy showed that during exposure on the ISS the pristine FEP sample reddened in some places and darkened on the whole, probably due to space radiation. Occasional 
dark specks in most of the images which occasionally reflect the light (Figure 8) may be metallic debris, most likely contamination debris which occurred during retrieval. Fabric near the edge of the sample holder appears to be more reddened than the bulk of the fabric surface, though the source of the reddening has not been identified. There were no areas of obvious mechanical damage to the fiber up to $100 \times$ in magnification.

The most revealing images were obtained in the FESEM. The pre-flight inspection noted the existence of cracks in the individual fibers, with filaments observed within them. These same cracks are noted in the post-flight images, and their structure looks the same. Similarly, the scuff marks and holes noted in the sample pre-flight were located post flight with no noticeable change. At magnification $>1000 \times$ a new feature was seen (Figure 9). The entire surface has been textured with pits ranging 1 to $4 \mu \mathrm{m}$ long and about half as wide. The long part of the pit tends to run across the fiber width, rather than its length. These features are also clearly visible in the AFM, which shows that there is additional structure in the floor of the pits. FESEM images taken from the samples pre-flight and the post-flight region protected by the samples holder show no such texture, confirming that the texturing is due to space exposure. The most likely cause of the texture is AO erosion.

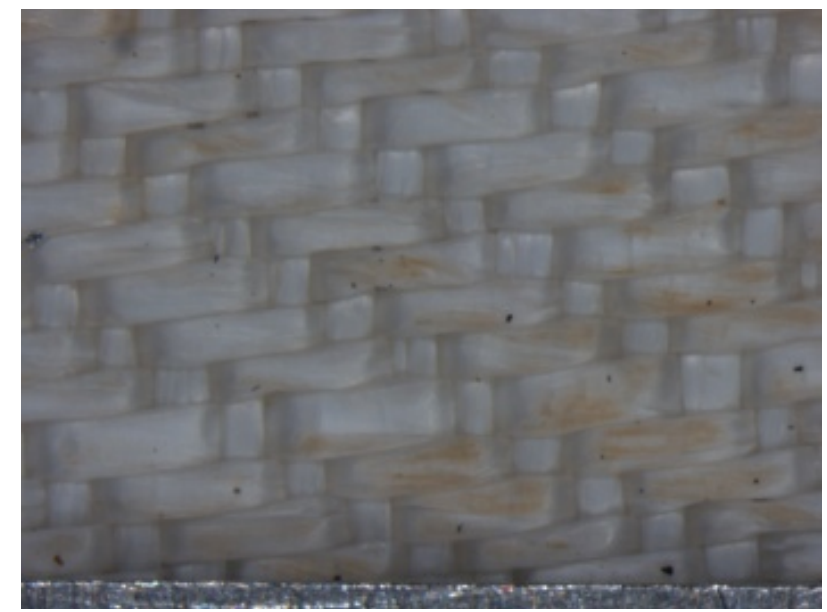

(a)

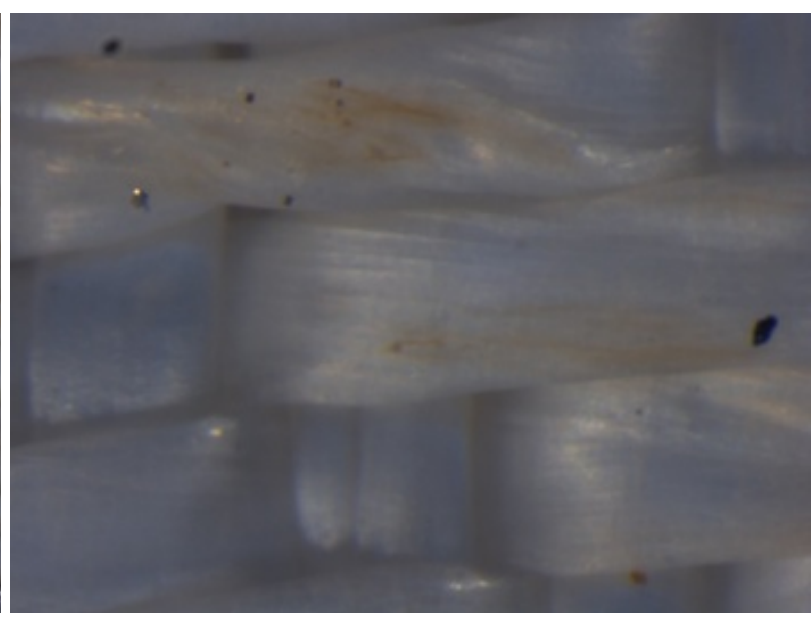

(b)

Figure 8.-Optical photomicrographs of pristine FEP at a magnification of $25 \times(\mathrm{a})$, and $100 \times(\mathrm{b})$ showing reddening of portions of the sample and debris

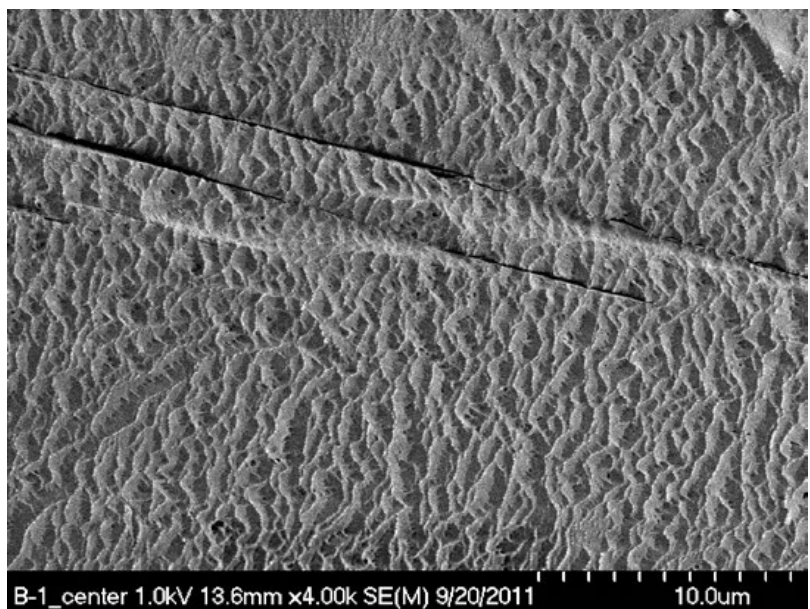

(a)

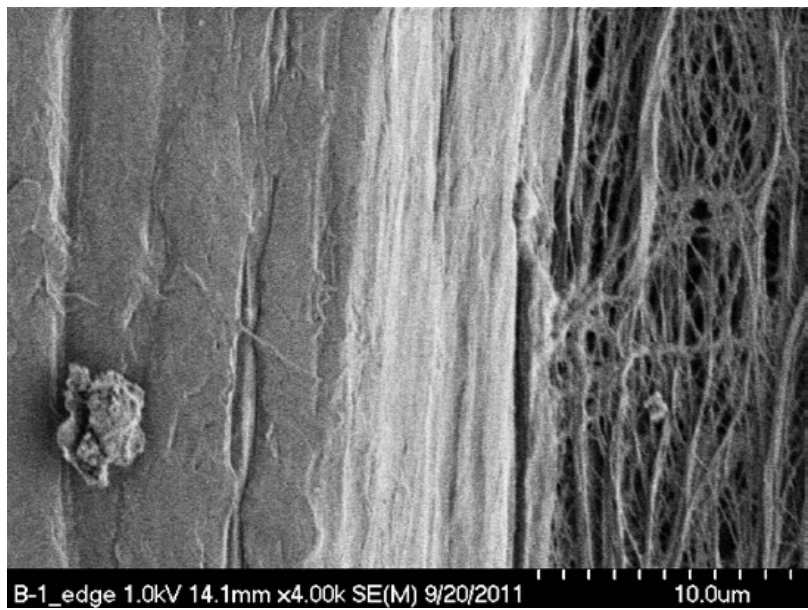

(b)

Figure 9.-FESEM photomicrographs of pristine FEP at a magnification of $4000 \times$ in the areas of the samples that were exposed (a), and protected by the samples holder (b). 


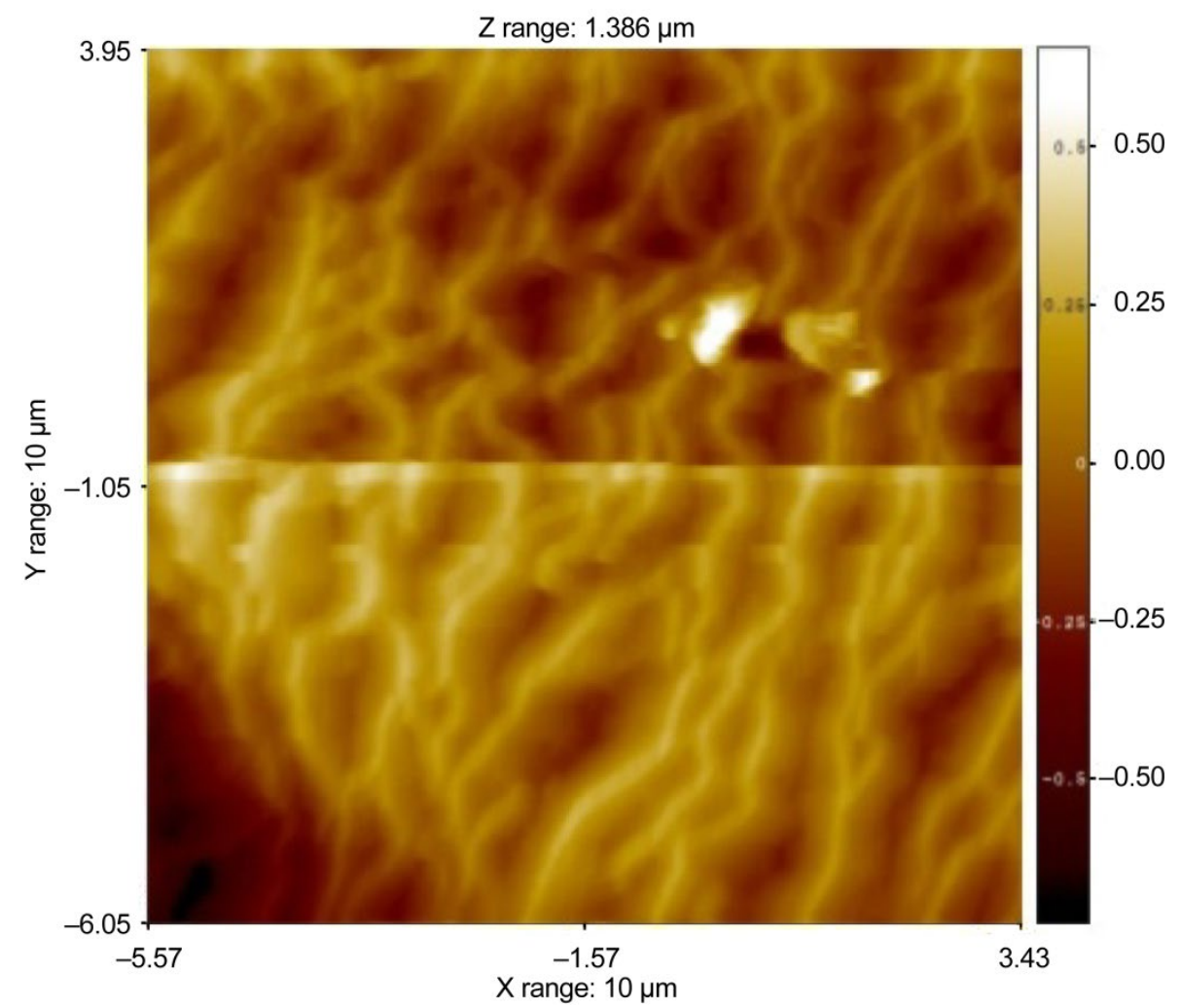

Figure 10.-AFM image of pristine FEP at a magnification of $10 \mu \mathrm{m}$ square in an area of the samples exposed to AO. The pit depth was determined from scale on the right to be consistent with the $0.6 \mu \mathrm{m}$ prediction of erosion. The line midway across the image is a raster imaging artifact.

Although the experiment was located on the wake face of MISSE, and nominally did not see AO, there was significant AO exposure nonetheless. The largest AO dose occurred when the ISS was reoriented, such as happened when docking to the Space Shuttle. At those times the "wake" face was turned $180^{\circ}$ and was exposed to the AO ram direction. The AO fluence on the wake face was monitored by several other MISSE-7 experiments. For example, Finckenor has determined the wake side AO fluence to be $2.9 \pm 0.3 \times 10^{20}$ atoms $/ \mathrm{cm}^{2}$ using the method of erosion rate of Kapton HN (Ref. 11). This is about 7 percent of the ram-side fluence of $4.2 \pm 0.1 \times 10^{21}$ atoms $/ \mathrm{cm}^{2}$. Expressed another way, during the 554 days of space exposure, the wake-side samples experienced the equivalent of more than 38 days of ram $\mathrm{AO}$ exposure.

The AO erosion yield for FEP films has been determined previously to be $2.00 \times 10^{-25} \mathrm{~cm}^{3} /$ atom (Ref. 12). This predicts that about $0.6 \mu \mathrm{m}$ should have been etched away from the surface. AFM imaging (Figure 10) suggests that the erosion pits have a depth consistent with that value.

\subsubsection{Abraded FEP Fabric}

Plastic deformation and smearing of the fibers caused by the dust abrasion technique was noted in the pre-flight characterization, and was clearly in evidence in the post-flight optical and FESEM microscopy (Figure 11). So too were areas of scuffing and scribing caused by the dust abrasion. At high magnification in the FESEM, etch structures that were noted in the pristine fabric were observed in the abraded areas as well. However, their morphology was somewhat different. Whereas the pristine fiber exhibited closed ring pits, the abraded fabric exhibited a series of nearly parallel filaments, which appear to protrude high off of the surface (Figure 12). No post-flight images of these samples could be obtained in the AFM, and it is speculated that these structures frustrated attempts to obtain AFM images. As with the pristine 
sample, FESEM images taken from the region protected by the sample holder show no such texture, confirming that the texturing is most likely caused by atomic oxygen.

The outstanding feature of the abraded FEP sample was a dark streak that that was about $1 \mathrm{~mm}$ wide and extended at an angle of about $40^{\circ}$ from the corner near the Bean sample across nearly the entire sample. In the optical microscope the streak appeared to be produced by the same process that darkens the entire exposed sample of the surface. The color appeared to be the same and at higher magnification it can be seen that the streak is not at all continuous. The colorant merely covers a larger fraction of the fabric surface in the streak region. The streak does not extend into the region covered by the sample holder. No evidence of a different structure, texture, or composition for the region of the streak was observed under the FESEM.

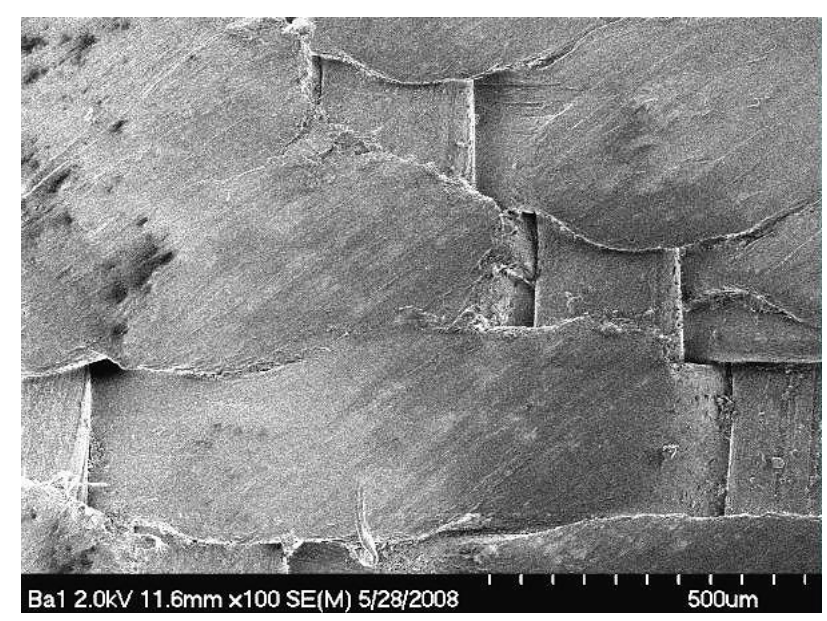

(a)

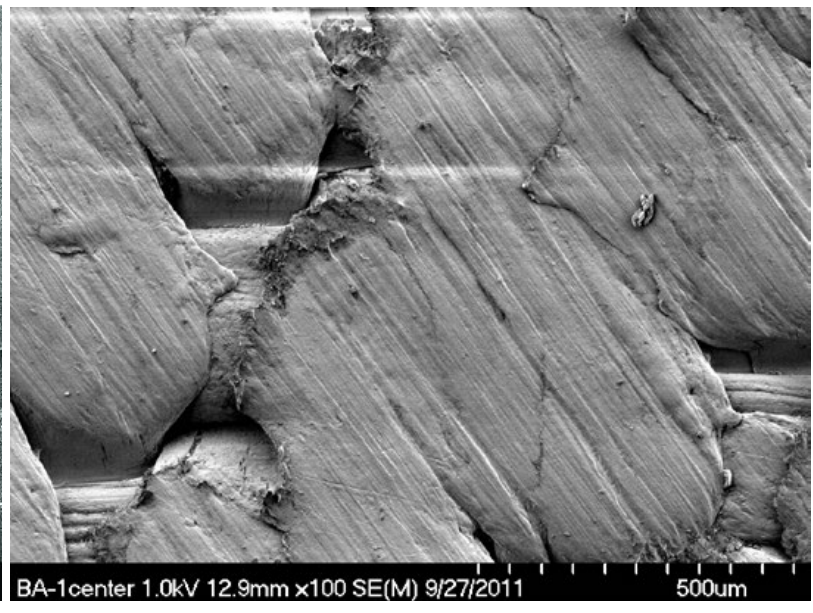

(b)

Figure 11.-FESEM photomicrographs of dust-abraded FEP at $100 \times$ showing smearing, scuffing, and scoring of the weft fibers pre-flight (a) and post-flight (b) .

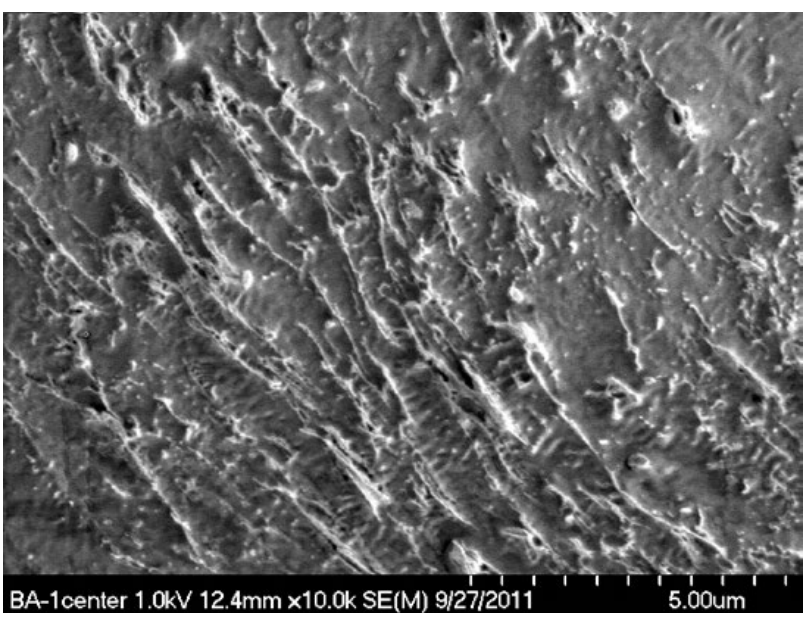

(a)

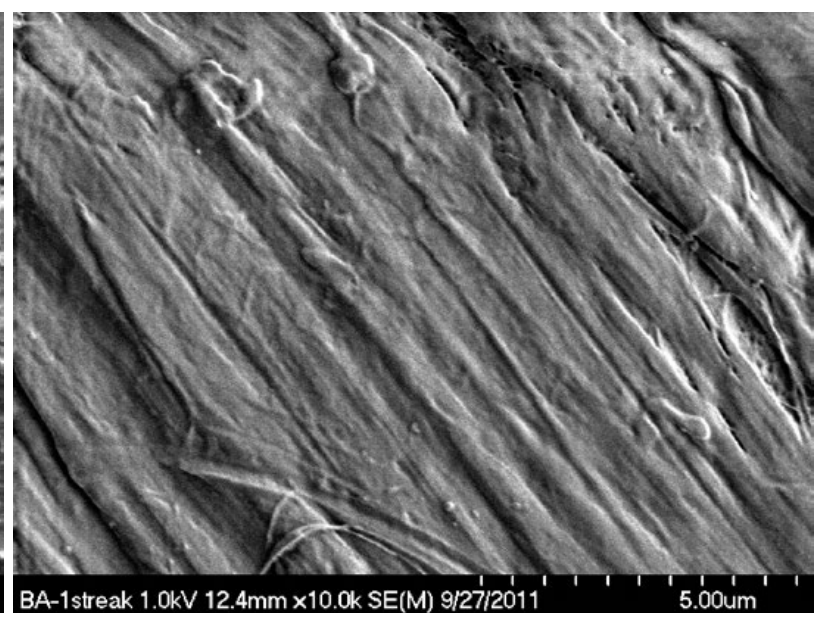

(b)

Figure 12.-FESEM photomicrographs of dust-abraded FEP at $10000 \times$ in the areas of the samples that were exposed (a), and protected by the sample holder (b). 


\subsubsection{Alan Bean Apollo FEP Fabric}

The optical and FESEM photomicrographs of the Bean sample pre-flight are consistent with those previously reported in the literature (Refs. 8 and 13). At high resolution the fibers exhibit little plastic deformation, but appear to be shredded and to have a lot of embedded dust. The embedded dust gives the fabric a much darker color than that imparted by the dust abrasion with the JSC-1A lunar simulant. This characteristic shredding of the fibers and embedded dust clearly seen in the post-flight samples was still present, however; as may be noted from Figure 13, there were many fewer places where shredded pieces of fiber stand up off of the fiber. Images at magnification $>1000 \times$ showed texturing that is similar to that seen on the other FEP fabric samples. Interestingly, there are regions where the etch pattern looks more like the pristine fiber, and other areas that look more like the dust abraded fiber (Figure 14).

\subsubsection{Pristine Ortho-Fabric}

As with FEP, optical microscopy revealed that the Ortho-fabric darkened and reddened upon space exposure. Interestingly, as can be seen in Figure 15, the weft had a much greater color change than the warp. On the pre-flight analysis triangular indentations scattered throughout the sample were noted, most likely a result of the weaving process. There were some cracks on the surface and filaments in some of the cracks. There were a few impact sites on the sample. One that left a $12 \mu \mathrm{m}$ wide crater is shown in Figure 16. No remnant of the projectile is seen. The texture seen within the crater implies that the impact occurred before the sample was exposed to a significant fluence of AO.

Despite the color change, at low magnification the post-flight fiber morphology appears unchanged from the pre-flight. But at magnification $>1000 \times$, like the FEP fibers, the surface appeared to have been etched by AO. The dimensions and morphology of the pits are the same as that seen in the FEP fabric. Once again the edge where the sample was protected under the sample holder was also very similar to the pre-flight sample.

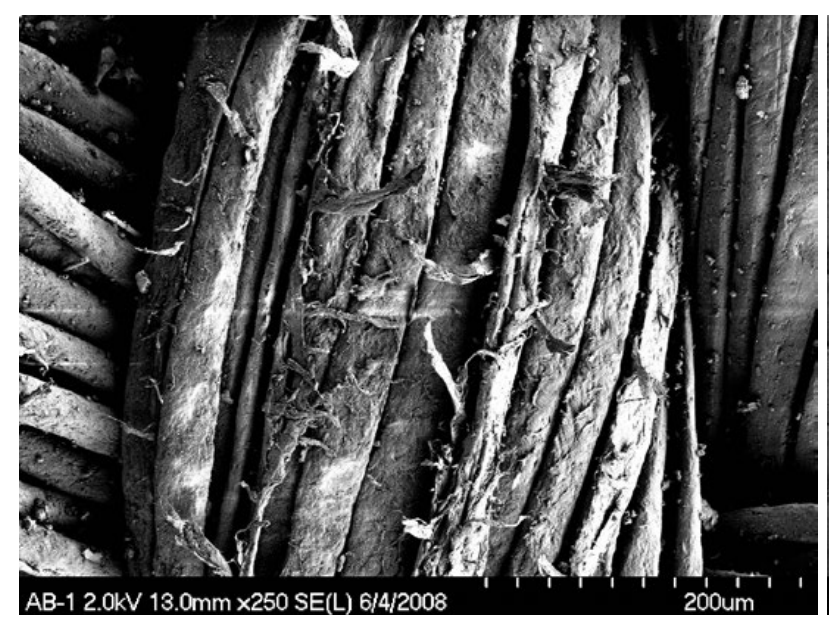

(a)

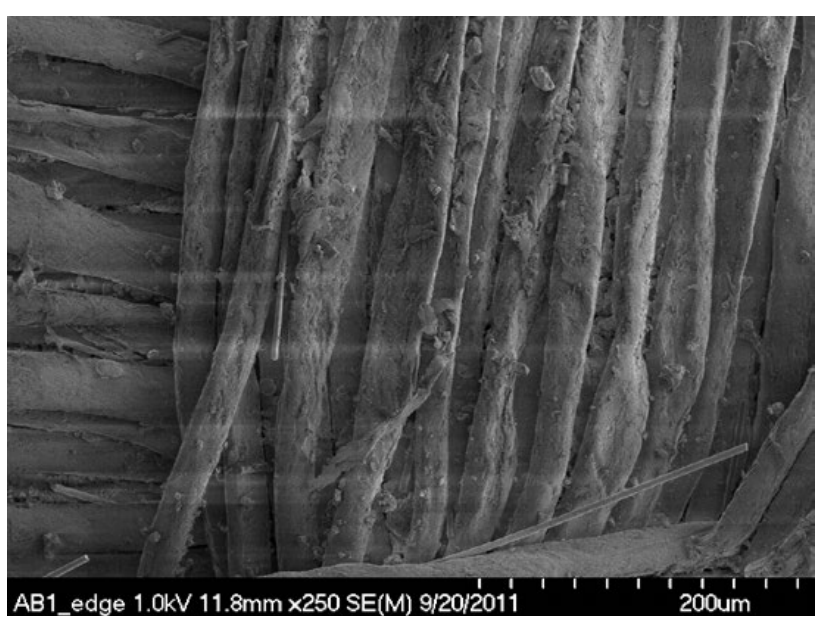

(b)

Figure 13.-Photomicrographs of the fabric from the left knee of Alan Bean's Apollo 12 spacesuit as it was returned from the Moon (a), and after 18 months of LEO exposure in the wake side of MISSE-7 (b). 


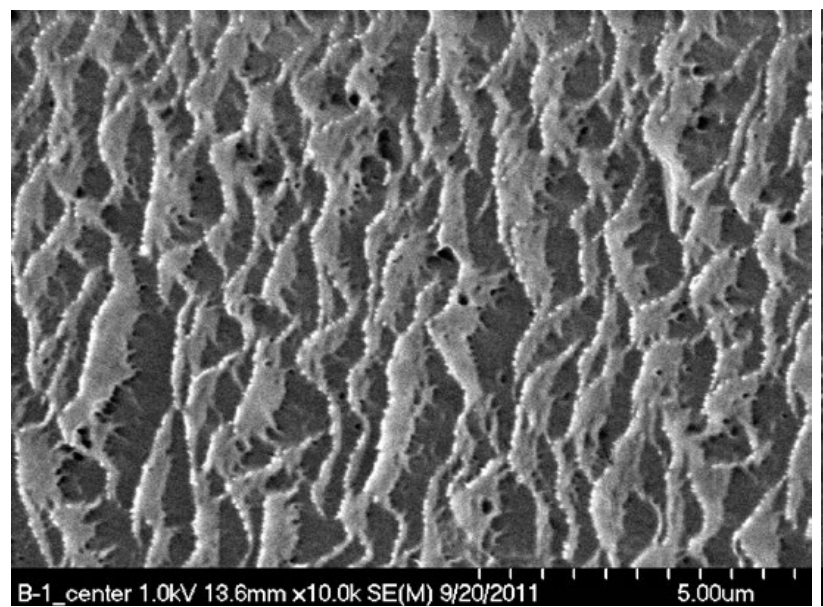

(a)

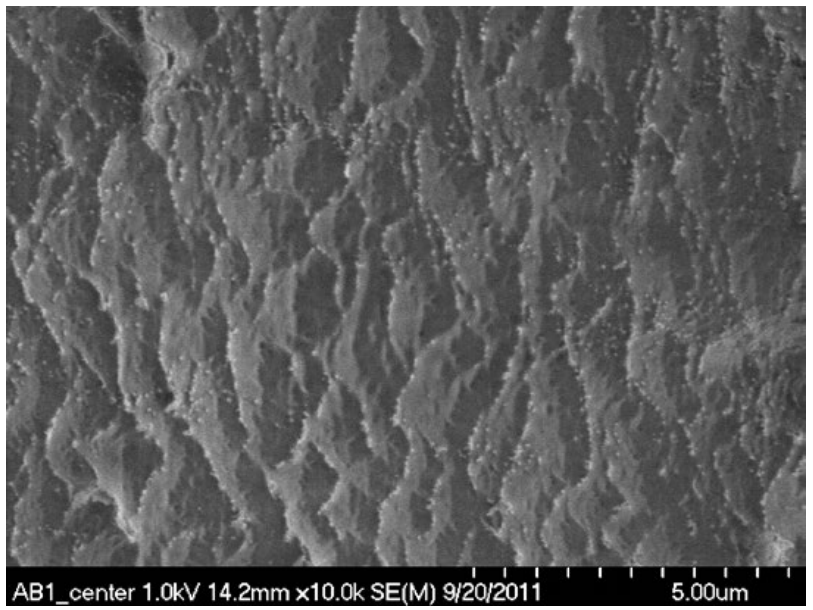

(c)

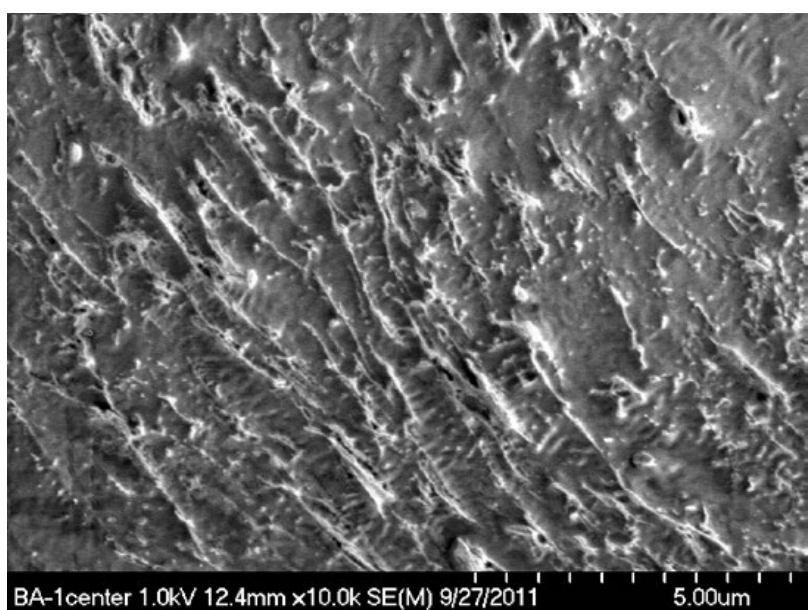

(b)

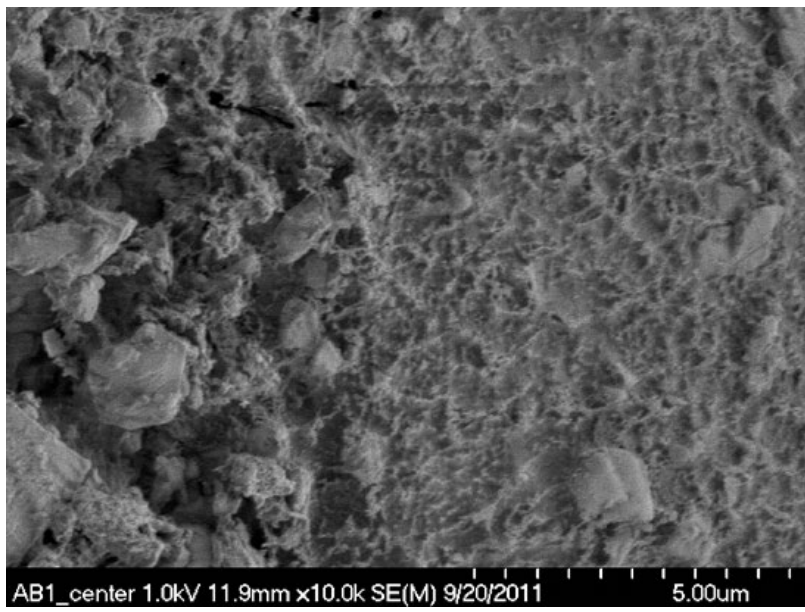

(d)

Figure 14.-Photomicrographs of pristine FEP (a), dust-abraded FEP (b) and fabric from the left knee of Alan Bean's Apollo 12 spacesuit (c), (d) after exposure on MISSE-7.

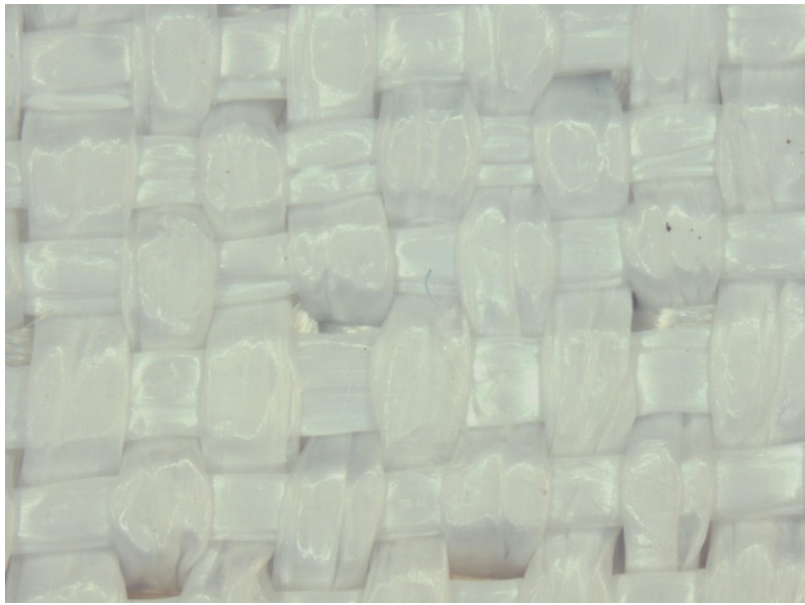

(a)

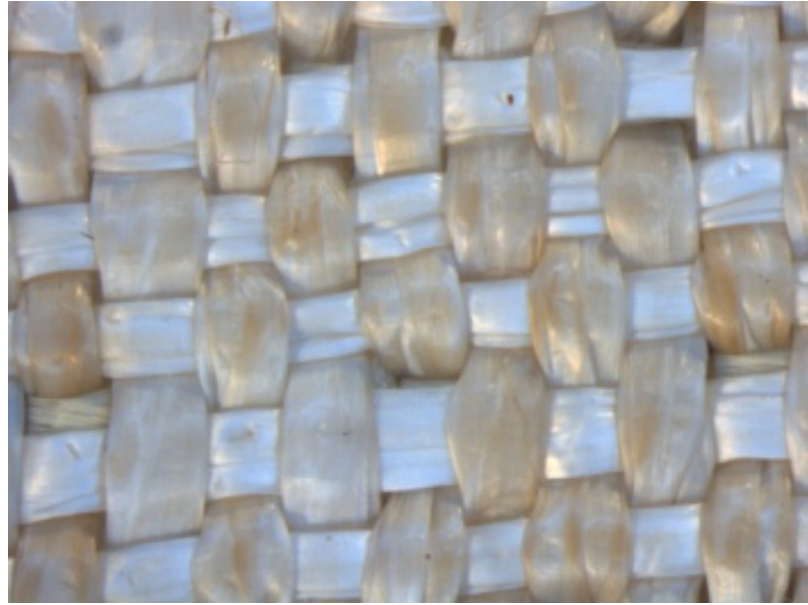

(b)

Figure 15.-Optical photomicrographs of pristine Ortho-fabric at $25 \times$ pre-flight (a) and post-flight (b) showing the preferential discoloration of the weft fibers. 


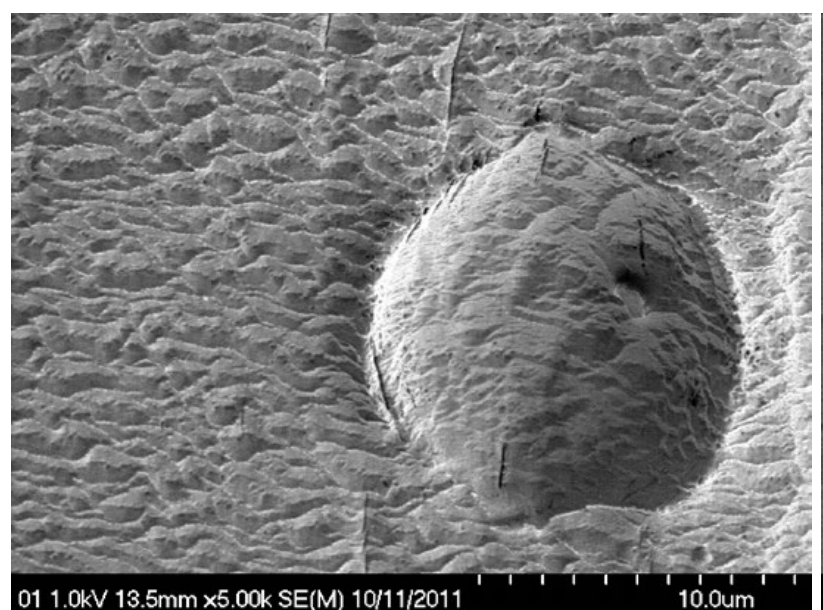

(a)

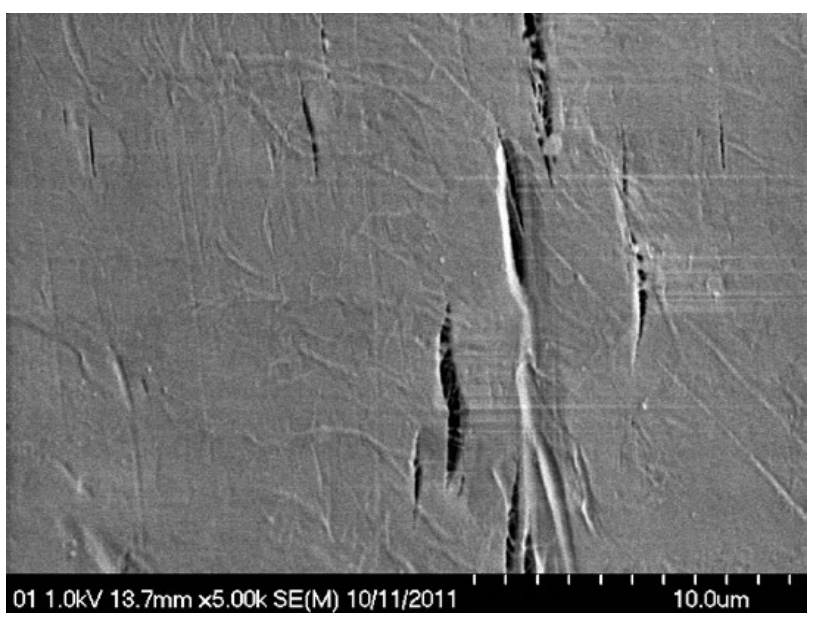

(b)

Figure 16.-FESEM photomicrographs of post-flight pristine Ortho-fabric at a magnification of $5000 \times$ in the areas of the samples that were exposed (a), and protected by the sample holder (b).

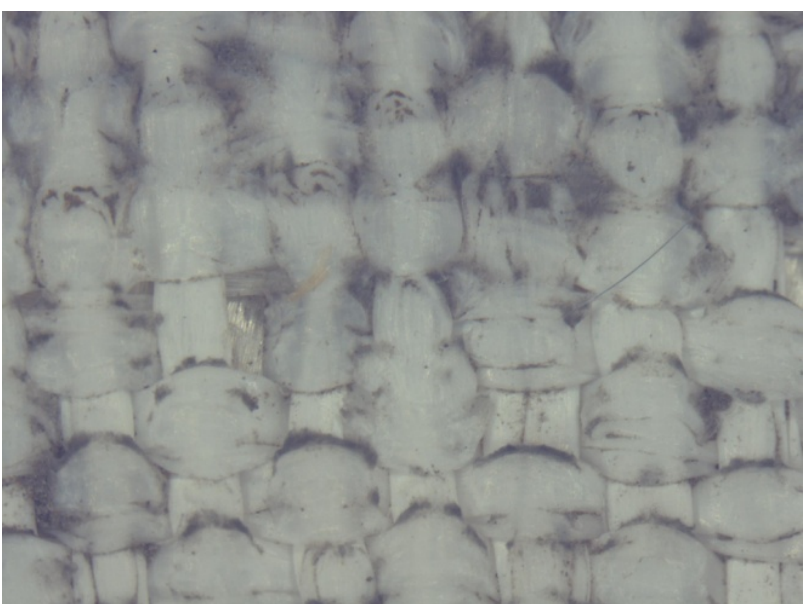

(a)

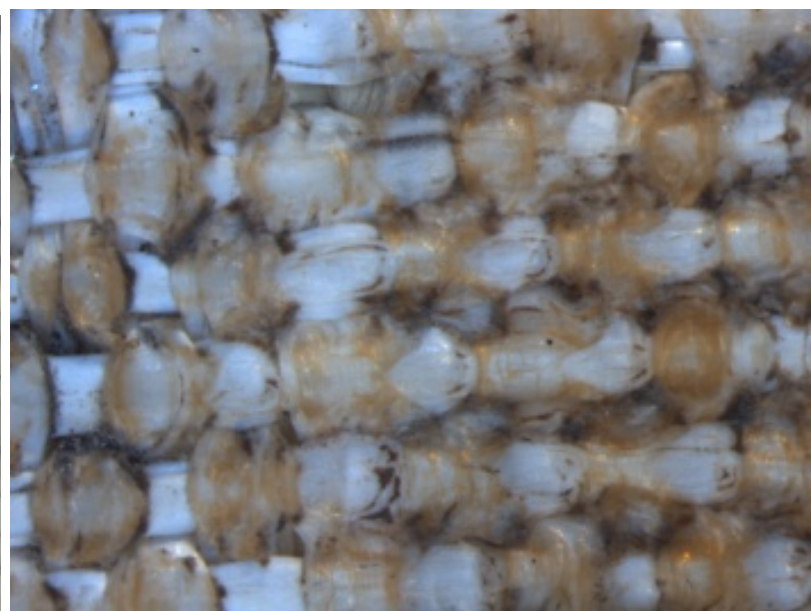

(b)

Figure 17.-Optical photomicrographs of dust-abraded Ortho-fabric at $25 \times$ pre-flight (a) and post-flight (b) showing the preferential discoloration of the weft fibers.

\subsubsection{Abraded Ortho-Fabric}

In the samples pre-flight, the weft (top) fibers were plastically deformed and scored by the dustabrasion process, and a considerable amount of dust remained trapped between the fibers. These features were also observed post-flight (Figure 17). Like the pristine Ortho-fabric, the abraded Ortho-fabric was darker and redder than pre-flight, with the color change being dominated by the weft. The fibers of this fabric were also etched, generally in patterns resembling the post-flight pristine Ortho-fabric. In some fibers, however, the damage was much more severe with a large fraction of the fiber being etched away through the entire volume of the fiber (Figure 18). Judging by the fiber diameter, these were probably Nomex fibers rather than PTFE. The atomic oxygen yield for Nomex is $10 \times$ that of PTFE, and so more than $4 \mu \mathrm{m}$ of the fiber might have eroded (Ref. 12). As with the other samples, the edge where the sample was protected under the sample holder appeared very similar to the pre-flight sample. 


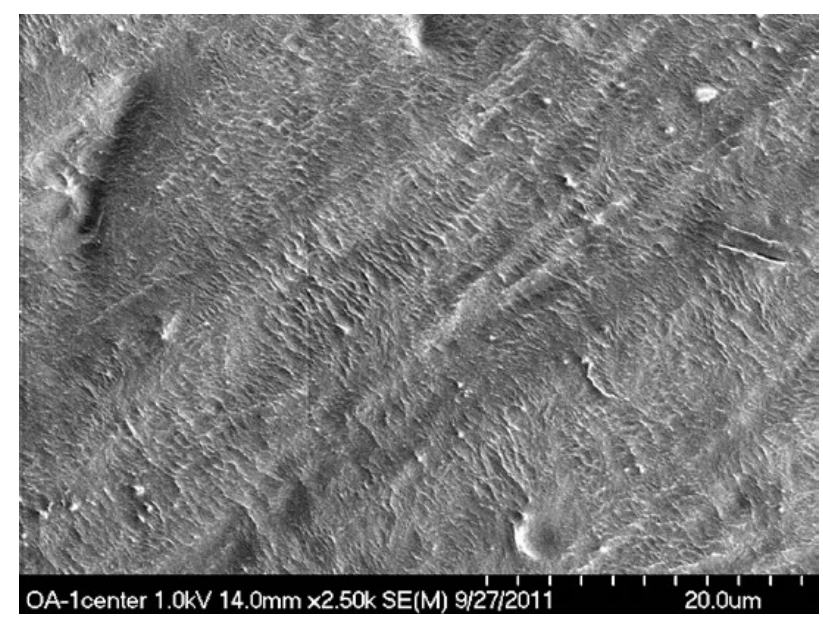

(a)

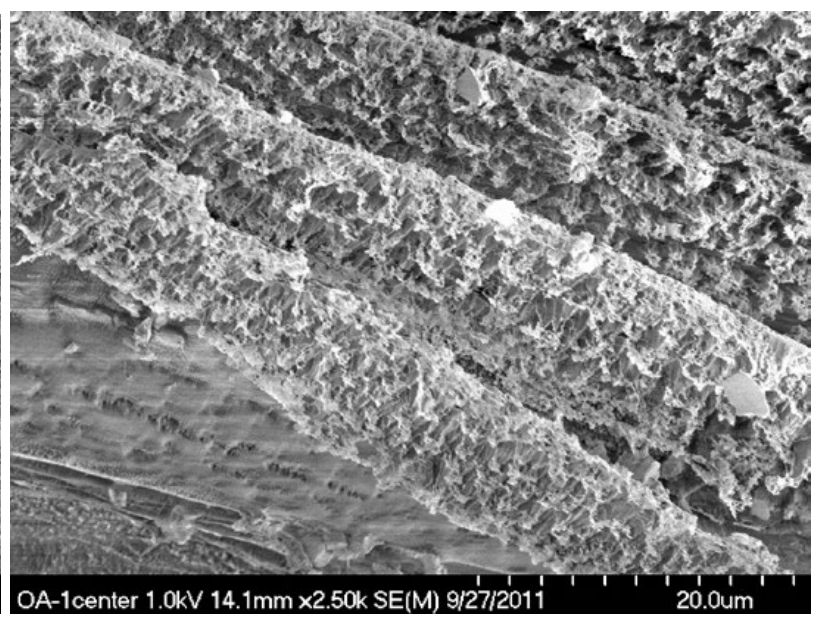

(b)

Figure 18.-FESEM photomicrographs of abraded Ortho-fabric at a magnification of $2500 \times$ in the areas of the samples that were exposed showing etching of the PTFE (a), and Nomex fibers (b).

\subsubsection{Twice Abraded Ortho-fabric}

The post-flight appearance of the doubly abraded Ortho-fabric was virtually identical to that of the singly abraded Ortho-fabric. Thus, doubling the number of abrasion cycles, from 8,000 to 16,000 had no measurable effect.

\subsection{Energy Dispersive X-Ray Spectroscopy (EDS)}

The EDS spectra of several samples were measured in order to determine whether the discoloration of the samples was due to radiation damage or contamination. Since EDS measures elemental composition of the samples, and FEP and PTFE signatures are simple and characteristic, containing only carbon and fluorine, contamination is easy to identify. EDS requires an electron beam of relatively high energy in order to excite inner shell electrons, so the samples were gold coated before the measurements were made. As a precaution, all samples were imaged thoroughly before the gold coating, and only a fraction of each sample was coated.

The most obvious candidate for contamination was the dust-abraded FEP fabric which contained a dark streak across it. The EDS spectrum taken of the area of the streak was identical with that of a characteristic area where the sample was exposed to the space environment, and an area where the sample was protected from the environment. The three spectra were virtually identical, showing only carbon and fluorine peaks with an approximate formula of $\mathrm{CF}_{2}$, characteristic of FEP.

Similar results were obtained for all three Ortho-fabric samples. This implies that the darkening was caused not by contamination, but by an interaction of the fabrics with radiation in the space environment. Darkening of Teflon upon radiation exposure, but not on AO exposure, is well established (Refs. 14 and 15). Although this seems the most likely explanation, and is consistent with the even appearance of the discoloration on five of the samples, it is difficult to explain how the streak could appear in the abraded FEP sample.

\subsection{Total Reflectance Spectroscopy}

The results of space exposure on the reflectance spectrum of the FEP fabrics are shown in Figure 19. There was little change in the $\rho(\lambda)$ for wavelengths longer than $800 \mathrm{~nm}$ in the pristine fabric (Figure 19 (a)). But there is a dramatic reduction in $\rho(\lambda)$ below $800 \mathrm{~nm}$ that becomes greater as $\lambda$ becomes shorter, hence the reddening. This darkening and reddening is in the visible region $(\lambda=400$ to $700 \mathrm{~nm})$ which is clearly shown in the optical photographs as discussed above. The $\alpha$ increased upon space exposure, as is 
shown in Table I. Although other measurements of the space degradation of fabrics have not been reported, the degradation of the aluminum backed FEP (AlFEP) bi-stem thermal shield of the HST over $8.3 \mathrm{yr}$ has been reported. The $\alpha$ of the pristine bi-stem AlFEP was $0.131 \pm 0.007$, its much lower value attributable to it being a smooth film as opposed to a bundle of fibers. On the solar-facing surface of the exposed material this increased to a value of $0.179 \pm 0.031$ and on the anti-solar facing surface to $0.127 \pm$ 0.011 (Ref. 16). This gives a ratio of $\alpha_{\text {post-flight }} / \alpha_{\text {pre-flight }}$ of 1.36 and 0.97 for the solar-facing and anti-solar facing respectively. This implicates solar particle radiation directly in the darkening since, unlike EM radiation, particle radiation does not strike the samples primarily line-of-sight from the Sun. The translucent white of the pre-flight pristine FEP fabric fibers had a higher $\alpha_{\text {pristine, }}$ but had a comparable $\alpha_{\text {post-flight }} / \alpha_{\text {pre-flight }}$ of 1.3. AO texturing of FEP shifts much of the specular $\alpha$ to diffuse, and also increases $\alpha$, but does not result in the reddening in the UV-visible region (Ref. 17).

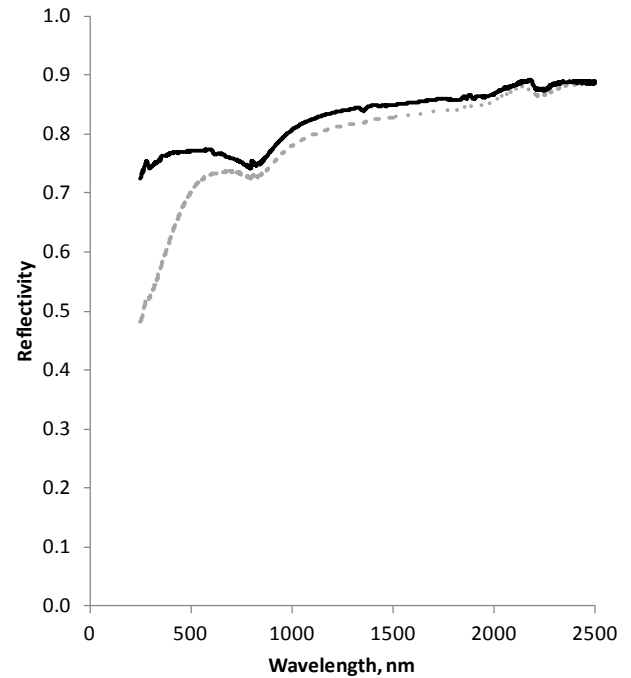

(a)

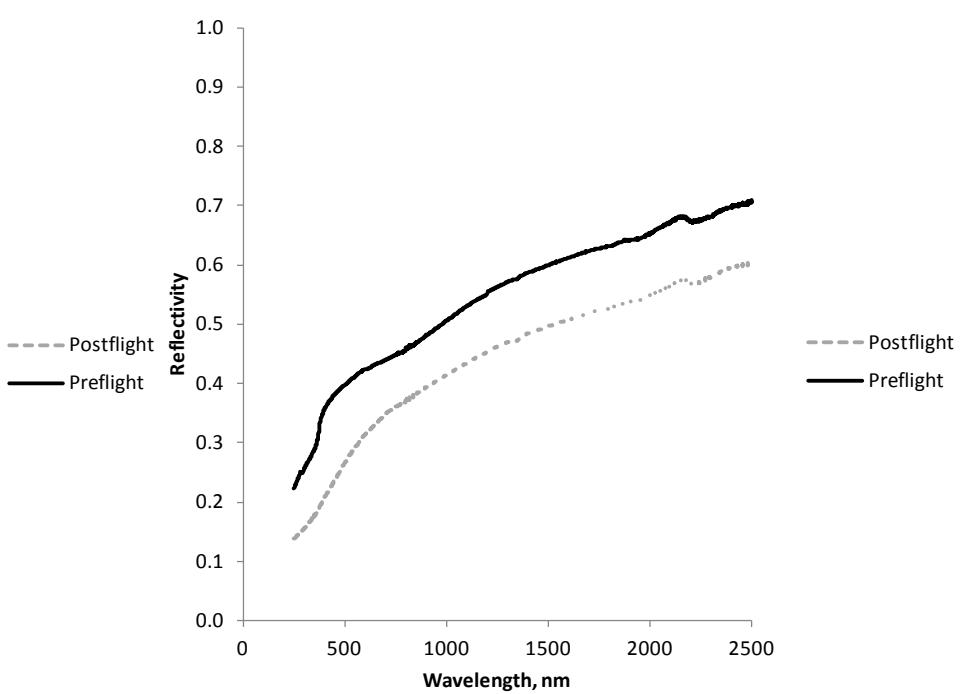

(b)

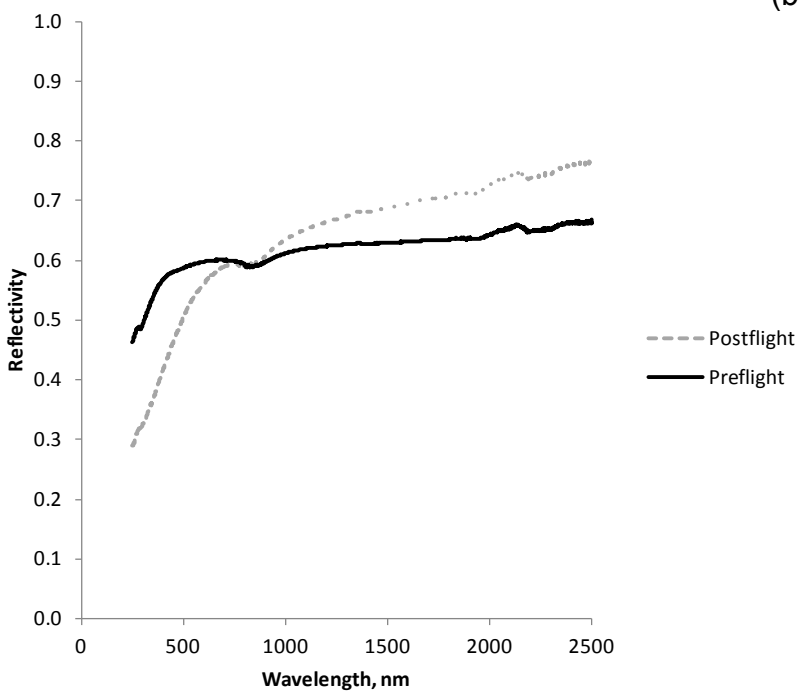

(c)

Figure 19.-Spectral $\rho(\lambda)$ of pre- and post-flight pristine FEP (a), dust abraded FEP (b), and Alan Bean suit (c). 
TABLE I.-INTEGRATED SOLAR ABSORPTANCE, $\alpha$, FOR THE SIX MISSE-7 SAMPLES, BEFORE AND AFTER SPACE EXPOSURE.

\begin{tabular}{|l|c|c|c|}
\hline \multicolumn{1}{|c|}{ Absorptance $(\alpha)$} & Pre-flight & Post-flight & $\alpha_{\text {post-flight }} / \alpha_{\text {pre-flight }}$ \\
\hline Pristine FEP & 0.22 & 0.28 & 1.27 \\
\hline Abraded FEP & 0.41 & 0.44 & 1.07 \\
\hline Alan Bean FEP & 0.55 & 0.65 & 1.18 \\
\hline Ortho-fabric & 0.24 & 0.33 & 1.38 \\
\hline Abraded Ortho-fabric & 0.44 & 0.48 & 1.09 \\
\hline 2x Abraded Ortho-fabric & 0.45 & 0.49 & 1.09 \\
\hline
\end{tabular}

The spectra of the pristine FEP (Figure 19(a)) can be used to help interpret the dust abraded FEP spectrum (Figure 19(b)). The functional form of the pre-flight and post-flight spectra for the dust abraded FEP sample above $500 \mathrm{~nm}$ is similar, except that the abraded sample is less reflective. In fact, Figure 20(a) shows that a simple rule of mixtures calculation, where 64 percent of the spectrum is due to the JSC-1AF spectrum (Ref. 18) and the remainder is due to the FEP fabric, results in a reasonable fit to the measured dust-abraded FEP spectrum.

However, this same rule of mixtures behavior clearly does not hold post-flight. The spectrum at $\lambda$ longer than $800 \mathrm{~nm}$ becomes increasingly reflective with $\lambda$ (Figure 19(b)). This is a spectral characteristic of lunar dust as well (Ref. 19). This spectral "reddening" can be seen in the Alan Bean suit spectrum shown in Figure 19(c), which was infused with lunar dust pre-flight. These data seem to indicate that radiation blocked by the Earth's atmosphere is essential in the reddening mechanism. Note that the $\rho(\lambda)$ decreased on space exposure, but uniformly across the spectrum by about 0.10 (Figure 19(c)).

Taken together, it appears that space exposure has three $\rho(\lambda)$ effects on dust abraded FEP fabric. First, exposure darkens and reddens FEP at 250 to $800 \mathrm{~nm} \lambda$, but has little or no effect on FEP at $\lambda>800$ $\mathrm{nm}$. The shortest $\lambda$ 's are most affected. Second, space exposure reddens the entrapped dust, with $\rho(\lambda)$ becoming increasing reflective at $\lambda>800 \mathrm{~nm}$. Third, space exposure darkens the dust, as evidenced by the decrease in $\rho(\lambda)$ of the already reddened lunar dust in the Alan Bean space suit fabric.

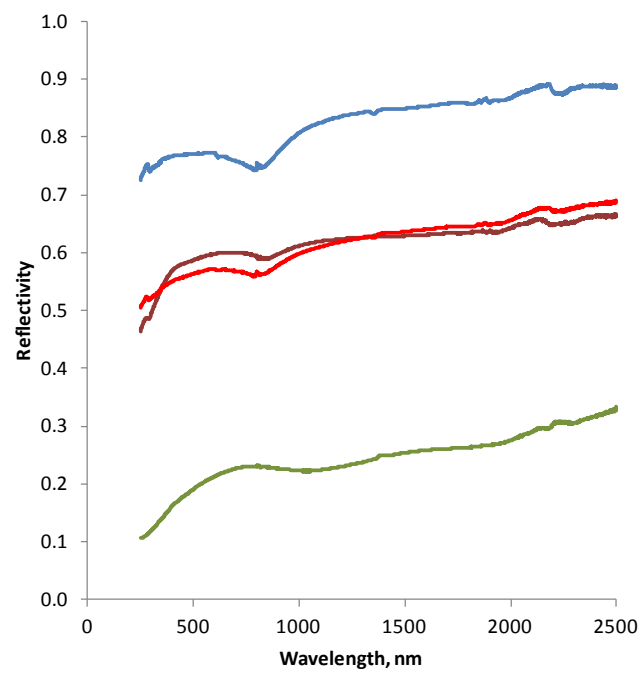

(a)

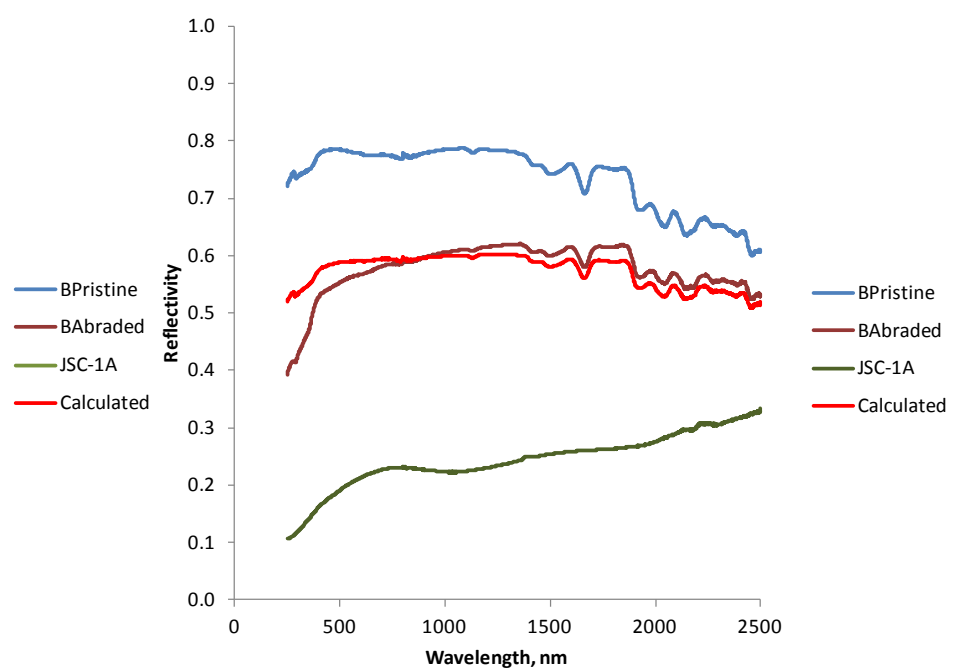

(b)

Figure 20.- Spectra of pre-flight $\rho(\lambda)$ of pristine fabric, lunar simulant JSC-1A, a linear combination of the two, and JSC-1A abraded fabric for FEP (a), and Ortho-fabric (b), shows that the simulant-abraded fabric spectra is reasonably well predicted by the linear combination of the pristine fabric and the lunar simulant. 


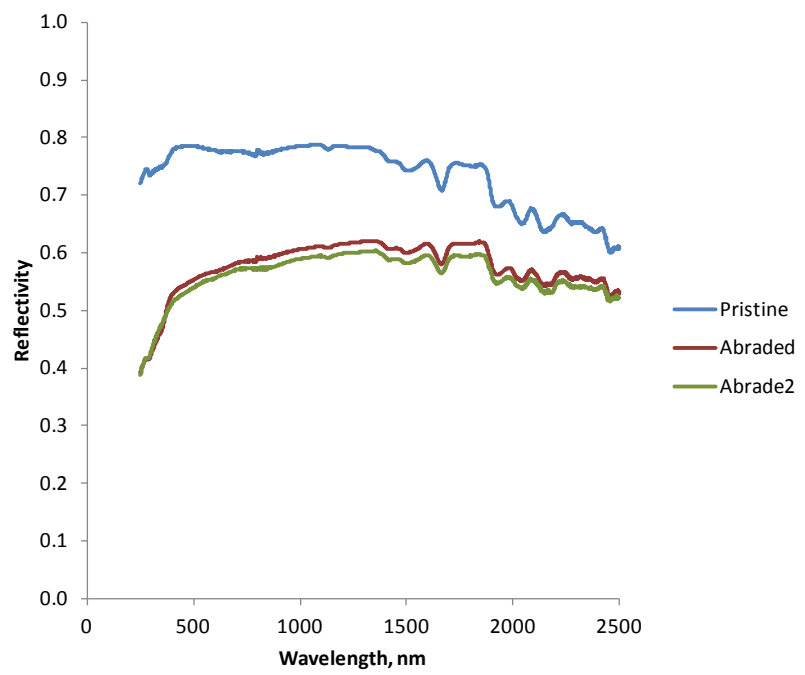

(a)

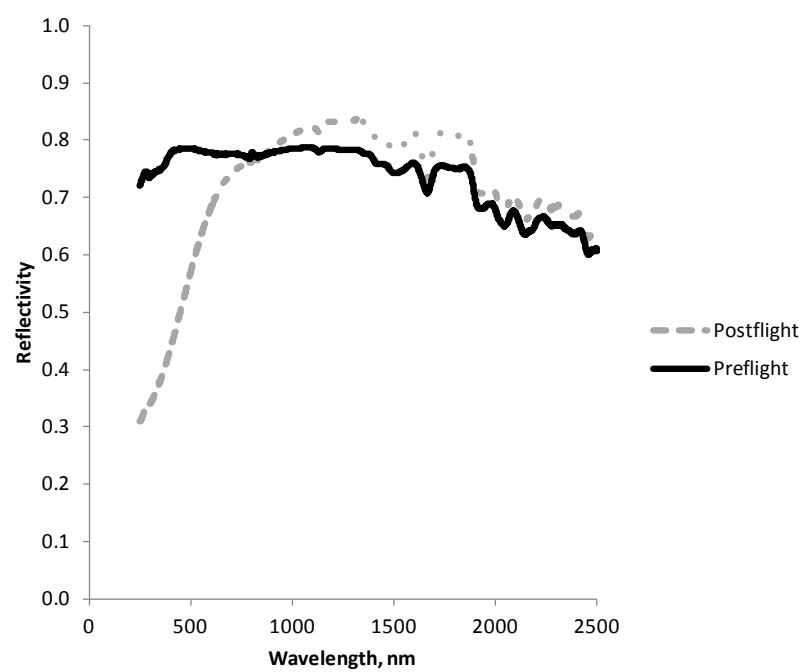

(b)

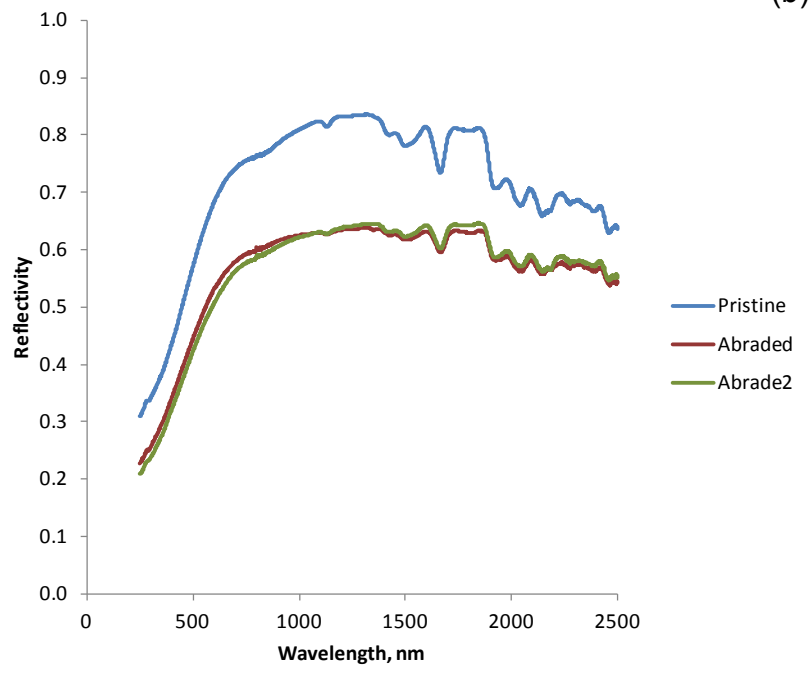

(c)

Figure 21.-Spectral $\rho(\lambda)$, of the three Ortho-fabric samples pre-flight (a), pre-flight compared to post-flight spectrum for pristine Ortho-fabric (b), and the three Ortho-fabric samples post-flight (c).

Figure 21(b) shows that the $\rho(\lambda)$ of Ortho-fabric slightly increases on space exposure for $\lambda>800 \mathrm{~nm}$, but drops dramatically below $800 \mathrm{~nm}$, and like the FEP the difference becomes greater as $\lambda$ becomes shorter. As with the FEP this darkening and reddening in the visible region (400 to $700 \mathrm{~nm}$ ) is also clearly shown in the optical photographs (Figure 6). The $\alpha$ of pristine Ortho-fabric increases by 38 percent upon space exposure (Table I).

Figure 21(c) shows the post-flight spectra of the pristine, abraded, and twice abraded Ortho-fabric. The reddening at $\lambda>800 \mathrm{~nm}$ that was so striking in the FEP spectrum does not appear in the Ortho-fabric spectrum. There is only a darkening of the spectrum on abrasion. The dust appears to have little if any effect on the spectrum, implying that the dust-abraded spectrum is dominated by abrasion damage, rather than by dust particles. 


\subsection{Tensile Test}

Tensile testing of single fibers from the fabrics was problematic. Since the flight specimens were so small, the length of fiber available for gripping was limited to 2 to $3 \mathrm{~mm}$ on each end. And since the fibers were FEP it was difficult to sufficiently grip the fibers over such a small length to exert a force large enough to break the fibers. Both the Ortho-fabric and the FEP had fibers much too large (200 to $600 \mu \mathrm{m})$ to break using our protocol. Only the filaments from the Alan Bean suit were sufficiently thin. The average filament diameters were measured to be $23 \pm 3 \mu \mathrm{m}$, and did not measurably change during exposure. This indicates that the AO etching observed in the microscopy was a surface effect and likely did not contribute significantly to mechanical degradation of the filaments.

The results of tensile testing of filaments from the Alan Bean sample are shown in Table II. The ultimate tensile strength of the filaments decreased by a factor of $4.1 \pm 1.4$, the elongation to failure decreased by $4.3 \pm 2.0$, and the modulus increased by a factor of $2.2 \pm 1.0$. Shimamura has shown that AO texturing in polyimide films can lead to deep local valleys and surface cracks which can decrease the tensile strength by as much as 30 percent (Ref. 20). But deep surface cracks were not observed in the microscopy, and since the AO exposure was not enough to significantly reduce the filament diameters, the bulk of the degradation was likely caused by exposure to space radiation. The mechanical properties of the FEP films of the thermal blankets of the HST degraded much more drastically than these samples, but they had much longer space exposure (6.8 yr as opposed to $1.5 \mathrm{yr}$ ) (Ref. 4).

TABLE II.-CHANGE IN TENSILE PROPERTIES OF ALAN BEAN FABRIC SAMPLES AFTER 18 MONTHS EXPOSURE TO THE LEO WAKE ENVIRONMENT

\begin{tabular}{|l|c|c|c|c|}
\hline & $\begin{array}{c}\text { No. } \\
\text { Fibers }\end{array}$ & $\begin{array}{c}\text { Ultimate Tensile Strength, } \\
\text { Pa }\end{array}$ & Elongation at Failure & $\begin{array}{c}\text { Young's Modulus, } \\
\text { Pa }\end{array}$ \\
\hline Pre-flight & 19 & $226 \pm 39$ & $1.03 \pm 0.24$ & $229 \pm 58$ \\
\hline Post-flight & 14 & $55 \pm 17$ & $0.24 \pm 0.10$ & $492 \pm 199$ \\
\hline
\end{tabular}

It should be noted that the sample was taken from the left knee of Alan Bean's suit, an area that perhaps would see more wear than any other part of the suit. Nevertheless, the degradation in tensile properties of lunar dust abraded spacesuit fabric when exposed to the space environment was substantial. This must be taken into account when planning for long term missions to the lunar surface. The fabric had been exposed to light wear, only being worn on the lunar surface for $7.8 \mathrm{hr}$, yet that combined with 18 months of space exposure decreased the tensile strength by a factor of four. Clearly, during a long mission, the integrity of the fabric would benefit from shielding it from solar radiation when it is not being worn. It is unfortunate that data were unable to be obtained for pristine fabrics in order to determine how much the dust abrasion changed the degradation properties. Somewhat larger samples including pristine FEP fabric are currently being exposed on MISSE-8, and may shed light on this.

\subsection{Conclusions}

Six samples of pristine and dust abraded outer layer spacesuit fabrics were exposed to the wake LEO environment on the ISS for 18 months. Comparison of pre- and post-flight characterizations showed that space radiation darkened and reddened all six fabrics. On space exposure, the $\alpha$ of the FEP fabric increased by 27 percent, and that of the Ortho-fabric increased by 38 percent. The $\alpha$ of FEP fabric abraded with JSC-1A increased by 7 percent, and JSC-1A abraded Ortho-fabric increased 9 percent. In both cases most of their spectra could be explained as a linear addition of the fabric and the dust, though the correlation did not hold in the visible and UV wavelengths for the Ortho-fabric. Spectroscopically, the lunar dust laden Apollo 12 sample darkened, but did not appreciably redden, though it appears redder to the eye. No evidence of contamination was seen in the EDS results, suggesting that the discoloration was due to radiation damage. Even though the samples were positioned on the wake side, because the ISS periodically reorients the samples were exposed to the equivalent of about 38 days of ram AO. Evidence 
for this was seen in the oxidation of silver-coated fasteners and the etching of fabric fibers. The erosion seen in the fibers was quantitatively consistent with previously reported values for the erosion yields of the materials. Space exposure decreased the ultimate tensile strength and elongation to failure of the Alan Bean Apollo 12 space suit filaments by a factor of four and increased the elastic modulus by a factor of two. The severity of the degradation of the fabric samples over the 18 month exposure period demonstrates the necessity to find ways to prevent or mitigate radiation damage to spacesuits when planning extended missions to the Moon.

\section{References}

1. J.R. Gaier, "The Effects of Lunar Dust on EVA Systems During the Apollo Missions," NASA/TM213610/REV1, 2005.

2. Apollo 12 Technical Crew Debriefing, December 1, 1969, Page 10-54.

3. J.A. Townsend, et al., "Hubble Space Telescope metalized Teflon ${ }^{\circledR}$ FEP thermal control materials: on orbit degradation and post-retrieval analysis," High Performance. Polymers 11(1) (1999) pp. 81-99.

4. J.A. Dever, et al., "Effects of Radiation and Thermal Cycling of Teflon ${ }^{\circledR}$ FEP," High Perf. Polymers 11(1) (1999) pp. 123-140.

5. J.R. Gaier, et al., "Pre-Flight Characterization of Samples for the MISSE-7 Spacesuit Fabric Exposure Experiment," NASA/TM-2009-215810.

6. J.R. Gaier, et al., "Post-Flight Characterization of Samples for the MISSE-7 Spacesuit Fabric Exposure Experiment," NASA/TM-2012-217651.

7. NASA Solicitation Number NNJ09289992R (2009).

8. J.R. Gaier, et al., "Abrasion of Candidate Spacesuit Fabrics by Simulated Lunar Dust," International Conference on Environmental Systems 2009, Paper 2009-01-2473. Also NASA/TM-2009-215800.

9. ASTM standard Test Method for Abrasion Resistance of Textile Fabrics (Rotary Platform, DoubleHead Method), D3884-09.

10. ASTM Standard Test Method for Tensile Strength and Young's Modulus of Fibers, C 1557-03, Reapproved 2008.

11. M.M. Finckenor (NASA MSFC) personal communication.

12. K.K. de Groh, et al., "MISSE 2 PEACE Polymers Atomic Oxygen Erosion Experiment on the International Space Station," Special Issue: High Performance Polymers 20 (2008) pp. 388-409.

13. R. Christoffersen, et al., "Lunar Dust Effects on Spacesuit Systems: Insights from the Apollo Spacesuits," NASA/TP-2009-214786.

14. K.K. de Groh, et al., "Analysis of Hubble Space Telescope Aluminized-Teflon Insulation Retrieved After 19 Years of Space Exposure," International Conference on Protection of Materials in the Space Environment-10," Okinawa, Japan (2011).

15. B.A. Banks, et al., "Atomic Oxygen Interactions with FEP Teflon and Silicones on LDEF," 1st LDEF Post-Retrieval Symposium, Kissimmee, FL (1991).

16. K.K. de Groh, et al., "Degradation of Hubble Space Telescope Aluminized-Teflon Bi-Stem Thermal Shields," High Performance Polymers 20 (2008), pp.410-428.

17. D.L. Waters, et al., "Changes in Optical and Thermal Properties of the MISSE 2 PEACE Polymers and Spacecraft Silicones," International Symposium on Materials in the Space Environment-11, Aixen-Provence, France (2009), proceedings in press.

18. J.R. Gaier, S. Ellis, and N. Hanks "Thermal Optical Properties of Lunar Dust Simulants and Their Constituents," AIAA 3rd Atmospheric and Space Environments Conference, 2011. AIAA-2011-3673. Also NASA/TM-2011-217232

19. Lunar Soil Characterization Consortium. Bidirectional reflectance spectra for lunar soils. Available at http://www.planetary.brown,edu/relabdocs/LSCCsoil.html, accessed April 2010.

20. H. Shimamura, et al., "Effects of Surface Cracks on Tensile Strength in Polyimide Films Exposed to Low Earth Orbit in MPAC\&SEED Experiment” ISMSE-11 Abstracts (2011) p 76. 



\begin{tabular}{|c|c|c|}
\hline \multicolumn{2}{|c|}{ REPORT DOCUMENTATION PAGE } & $\begin{array}{l}\text { Form Approved } \\
\text { OMB No. 0704-0188 }\end{array}$ \\
\hline \multicolumn{3}{|c|}{ 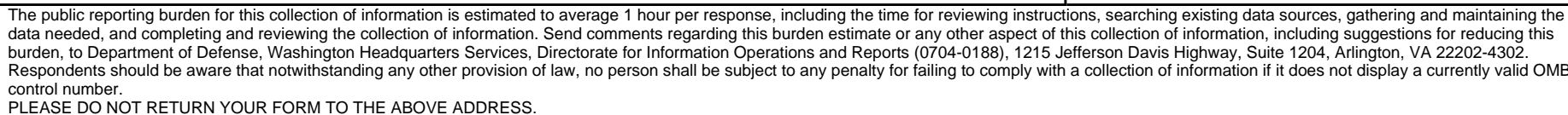 } \\
\hline $\begin{array}{l}\text { 1. REPORT DATE (DD-MM-YYYY) } \\
01-08-2012\end{array}$ & $\begin{array}{l}\text { 2. REPORT TYPE } \\
\text { Technical Memorandum }\end{array}$ & 3. DATES COVERED (From - To) \\
\hline \multirow{3}{*}{\multicolumn{2}{|c|}{$\begin{array}{l}\text { 4. TITLE AND SUBTITLE } \\
\text { Degradation of Spacesuit Fabrics in Low Earth Orbit }\end{array}$}} & 5a. CONTRACT NUMBER \\
\hline & & 5b. GRANT NUMBER \\
\hline & & 5c. PROGRAM ELEMENT NUMBER \\
\hline \multirow{3}{*}{\multicolumn{2}{|c|}{$\begin{array}{l}\text { 6. AUTHOR(S) } \\
\text { Gaier, James, R.; Baldwin, Sammantha, M.; Folz, Angela, D.; Waters, Deborah, L.; McCue, } \\
\text { Terry, R.; Jaworske, Donald, A.; Clark, Gregory, W.; Rogers, Kerry, J.; Batman, Brittany; } \\
\text { Bruce, John; Mengesu, Tsega }\end{array}$}} & 5d. PROJECT NUMBER \\
\hline & & 5e. TASK NUMBER \\
\hline & & $\begin{array}{l}\text { 5f. WORK UNIT NUMBER } \\
\text { WBS 936374.04.08.03 }\end{array}$ \\
\hline \multicolumn{2}{|c|}{$\begin{array}{l}\text { 7. PERFORMING ORGANIZATION NAME(S) AND ADDRESS(ES) } \\
\text { National Aeronautics and Space Administration } \\
\text { John H. Glenn Research Center at Lewis Field } \\
\text { Cleveland, Ohio 44135-3191 }\end{array}$} & $\begin{array}{l}\text { 8. PERFORMING ORGANIZATION } \\
\text { REPORT NUMBER } \\
\text { E-18357 }\end{array}$ \\
\hline \multirow{2}{*}{\multicolumn{2}{|c|}{$\begin{array}{l}\text { 9. SPONSORING/MONITORING AGENCY NAME(S) AND ADDRESS(ES) } \\
\text { National Aeronautics and Space Administration } \\
\text { Washington, DC 20546-0001 }\end{array}$}} & $\begin{array}{l}\text { 10. SPONSORING/MONITOR'S } \\
\text { ACRONYM(S) } \\
\text { NASA }\end{array}$ \\
\hline & & $\begin{array}{l}\text { 11. SPONSORING/MONITORING } \\
\text { REPORT NUMBER } \\
\text { NASA/TM-2012-217682 }\end{array}$ \\
\hline \multicolumn{3}{|c|}{$\begin{array}{l}\text { 12. DISTRIBUTION/AVAILABILITY STATEMENT } \\
\text { Unclassified-Unlimited } \\
\text { Subject Categories: } 54 \text { and } 27 \\
\text { Available electronically at http://www.sti.nasa.gov } \\
\text { This publication is available from the NASA Center for AeroSpace Information, 443-757-5802 }\end{array}$} \\
\hline
\end{tabular}

\section{SUPPLEMENTARY NOTES}

\section{ABSTRACT}

Six samples of pristine and dust-abraded outer layer spacesuit fabrics were included in the Materials International Space Station Experiment-7, in which they were exposed to the wake-side low Earth orbit environment on the International Space Station (ISS) for 18 months in order to determine whether abrasion by lunar dust increases radiation degradation. The fabric samples were characterized using optical microscopy, optical spectroscopy, field emission scanning electron microscopy, atomic force microscopy, and tensile testing before and after exposure on the ISS. Comparison of pre- and post-flight characterizations showed that the environment darkened and reddened all six fabrics, increasing their integrated solar absorptance by 7 to 38 percent. There was a decrease in the ultimate tensile strength and elongation to failure of lunar dust abraded Apollo spacesuit fibers by a factor of four and an increase in the elastic modulus by a factor of two.

\section{SUBJECT TERMS}

Space suits; Fabrics; Degradation; Dust

\begin{tabular}{|c|c|c|c|c|c|}
\hline \multicolumn{3}{|c|}{ 16. SECURITY CLASSIFICATION OF: } & \multirow{2}{*}{$\begin{array}{l}\text { 17. LIMITATION OF } \\
\text { ABSTRACT } \\
\text { UU }\end{array}$} & \multirow{2}{*}{$\begin{array}{l}\text { 18. NUMBER } \\
\text { OF } \\
\text { PAGES } \\
28\end{array}$} & \multirow{2}{*}{$\begin{array}{l}\text { 19a. NAME OF RESPONSIBLE PERSON } \\
\text { STI Help Desk (email:help@sti.nasa.gov) } \\
\text { 19b. TELEPHONE NUMBER (include area code) } \\
\text { 443-757-5802 }\end{array}$} \\
\hline $\begin{array}{l}\text { a. REPORT } \\
U\end{array}$ & $\begin{array}{l}\text { b. ABSTRACT } \\
\text { U }\end{array}$ & $\begin{array}{l}\text { c. THIS } \\
\text { PAGE } \\
\text { U }\end{array}$ & & & \\
\hline
\end{tabular}



